\title{
Optimizing nanostructure and constructing heterostructure via Mo/W incorporation to improve electrochemical properties of NiCoP for hybrid supercapacitors
}

\author{
Quan Zong ${ }^{1,2 \dagger^{*}}$, Daiwen $\mathrm{Tao}^{2 \dagger}$, Hui Yang ${ }^{2,3}$, Jianhui Zhan ${ }^{2}$, Xiong $\mathrm{Liu}^{2}$, Jiangying Wang \\ Qilong Zhang ${ }^{2,3^{*}}$ and Guozhong $\mathrm{Cao}^{4^{*}}$
}

\begin{abstract}
Transition metal phosphides (TMPs) are promising battery-type electrodes for hybrid supercapacitors (HSCs) due to their high electrical conductivity and electrochemical activity. Constructing TMPs with fast kinetics and stable structure is requisite to realize high-performance HSCs but remains a challenge. Herein, we incorporate Mo (or W) into NiCoP to form Ni-Co-Mo-P (or Ni-Co-W-P) heterostructures with a unique three-dimensional (3D) open morphology and modified electronic structure. Electrochemical analyses and density functional theory (DFT) calculations reveal that the incorporation of $\mathrm{Mo} / \mathrm{W}$ enables $\mathrm{NiCoP}$ with optimized nanostructure, high conductivity, abundant reaction active sites and enhanced reaction kinetics. As a result, the designed Ni-Co-Mo-P heterostructure delivers a high areal capacity of $4.08 \mathrm{C} \mathrm{cm}^{-2}\left(703 \mathrm{C} \mathrm{g}^{-1}\right)$ at $2 \mathrm{~mA} \mathrm{~cm}$ and $3.25 \mathrm{C} \mathrm{cm}^{-2}$ at $30 \mathrm{~mA} \mathrm{~cm}{ }^{-2}$ with a good cycling stability, superior to those of NiCoP and Ni-Co-W-P counterparts. The practical feasibility of the $\mathrm{Ni}-\mathrm{Co}-\mathrm{Mo}-\mathrm{P}$ heterostructure is further demonstrated by an energy conversion and storage system consisting of commercial solar cell and Ni-Co-Mo-P// activated carbon (AC) device, which could obtain a high energy density of $53.3 \mathrm{~W} \mathrm{~h} \mathrm{~kg}$ at a power density of $800 \mathrm{~W} \mathrm{~kg}$. All-solid-state Ni-Co-Mo-P//AC device further illustrates the superior flexibility and makes a strong candidate for wearable energy storage electronics.
\end{abstract}

Keywords: NiCoP, Mo/W incorporation, DFT calculations, hybrid supercapacitors

\section{INTRODUCTION}

Supercapacitors (SCs) have been regarded as one of the most promising energy storage devices due to their high power density, long lifespan, high safety and low cost [1-4]. However, compared with rechargeable batteries, the practical applications of SCs are often restricted by low energy density $(E)[5,6]$. Based on the equation: $E=1 / 2 C V^{2}$ (C: capacitance; $V$ : voltage), both high capacity and wide voltage window can realize large energy density. In this regard, assembling hybrid SCs (HSCs) consisting of one battery-type electrode and one capacitive electrode could obtain combined advantages of batteries (e.g., high energy density) and SCs (e.g., high power density) [7,8]. For aqueous HSCs, the voltage window is also determined by the hydrogen evolution reaction (HER) and oxygen evolution reaction (OER) overpotentials of electrodes $[9,10]$. Therefore, more efforts have been put on developing novel materials with excellent physicochemical properties.

Transition metal oxides $\left(\mathrm{M}_{x} \mathrm{O}_{y}, \mathrm{M}=\mathrm{V}, \mathrm{Mn}, \mathrm{Fe}, \mathrm{Co}, \mathrm{Ni}, \mathrm{Cu}\right.$, etc.) have been widely investigated as electrodes for SCs due to their high theoretical capacity [11-13]. However, the poor electrical conductivity still hinders their further application seriously $[5,14]$. In order to find promising materials as cathodes for HSCs toward practical applications, researchers have devoted enormous efforts toward designing novel materials or structures with satisfactory electrochemical properties, such as transition metal hydroxides (NiFe layered double hydroxide (LDH)), chalcogenides $\left(\mathrm{Cu}_{2} \mathrm{MoS}_{4}, \mathrm{MoSe}_{2}\right)$, phosphides $\left(\mathrm{Ni}_{2} \mathrm{P}, \mathrm{CoP}\right)$ and layered MXenes $\left(\mathrm{Ti}_{3} \mathrm{C}_{2}\right)$ [15-19]. Among these electrode materials, transition metal phosphides (TMPs) have attracted wide interest, which exhibit high conductivity, high electrochemical activity and metalloid properties because there is no band gap in metal phosphides [20]. Moreover, bimetallic NiCoP delivers higher electrochemical properties than the single-metal counterparts due to the synergistic effects between various ions. In addition, both covalent and metallic metal-phosphorus bonds exist in $\mathrm{NiCoP}$ in which covalent bonds are responsible for the storage of charges while metallic bonds contribute to high electrical conductivity $[21,22]$. These advantages make NiCoP a promising electrode material for HSCs. However, the application of the NiCoP electrode is still limited by relatively low specific capacity and fast capacity decay due to insufficient reaction active sites and sluggish reaction kinetics.

Introducing foreign atoms into TMPs to form heterostructures is an effective strategy to increase active sites and enhance reaction kinetics $[23,24]$. For instance, incorporating Co cations into $\mathrm{Ni}_{5} \mathrm{P}_{4}$ could generate two new phases (hexagonal

\footnotetext{
${ }^{1}$ College of Materials and Chemistry, China Jiliang University, Hangzhou 310018, China

${ }^{2}$ School of Materials Science and Engineering, State Key Lab Silicon Mat, Zhejiang University, Hangzhou 310027, China

${ }^{3}$ ZJU-Guangxi-ASEAN Innovation \& Research Center, Nanning 530022, China

${ }^{4}$ Department of Materials Science and Engineering, University of Washington, Seattle, WA 98195, USA

$\dagger$ These authors contributed equally to this work.

* Corresponding authors (emails: quanzong@cjlu.edu.cn (Zong Q); mse237@zju.edu.cn (Zhang Q); gzcao@uw.edu (Cao G))
} 
$\mathrm{NiCoP}$ and orthorhombic $\mathrm{CoP}$ ). Moreover, the heterojunction between $\mathrm{NiCoP}$ and $\mathrm{CoP}$ leads to the electron redistribution and change of coordination environment. The abundant heterointerface between $\mathrm{CoP}$ and $\mathrm{NiCoP}$ not only avoids high junction resistance to accelerate reaction kinetics during the electrochemical process, but also provides rich redox reactive sites to promote fast ion and charge transfer [25]. Besides the formation of heterostructures, the introduction of foreign elements may cause a morphology change of materials [26]. For example, three-dimensional (3D) hierarchical nanowires-decorated nanosheet cluster arrays were formed after introducing $\mathrm{Mn}$ element into CoP because it is beneficial for the growth of nanosheets [27]. The nanowires-decorated nanosheet arrays are more easily accessible to electrolytes, thus accelerating the penetration of electrolytes. Many elements (such as $3 \mathrm{~d}$ metals of $\mathrm{Fe}, \mathrm{Co}, \mathrm{Ni}$ and $\mathrm{Zn}$ ) have been proved to be able to improve the electrochemical property of TMPs. However, there are few studies on high-valence metal elements (Mo/W)-incorporated $\mathrm{NiCoP}$ and their electrochemical performance is still waiting to be dug out [28-30].

In this work, high-valence Mo or $\mathrm{W}$ elements are introduced into NiCoP nanoarrays via a facile hydrothermal method to prepare Ni-Co-Mo-P or Ni-Co-W-P nanoarrays. The effects of $\mathrm{Mo} / \mathrm{W}$ elements on the morphology, phase, electronic structure and electrochemical property of $\mathrm{NiCoP}$ nanoarrays are systematically studied by experimental and theoretical approaches. Compared with NiCoP and Ni-Co-W-P nanoarrays, the Ni-CoMo-P heterostructure possesses higher specific capacity, enhanced rate capability and improved cycling stability due to the increased reaction active sites, high conductivity and fast reaction kinetics caused by Mo incorporation. Being paired with the activated carbon (AC) anode, the aqueous Ni-Co-Mo-P//AC device delivers a high energy density of $53.3 \mathrm{~W} \mathrm{~h} \mathrm{~kg}^{-1}$ at a power density of $800 \mathrm{~W} \mathrm{~kg}^{-1}$ and demonstrates excellent cycling durability (a capacity retention of $90 \%$ after 5000 cycles). More importantly, the assembled all-solid-state Ni-Co-Mo-P//AC device displays a good flexibility. Our work may shed new insights into developing high-performance electrodes for flexible HSCs and other energy storage devices.

\section{EXPERIMENTAL SECTION}

\section{Synthesis of Ni-Co-Mo-P and Ni-Co-W-P nanoarrays}

All chemical reagents were used without any further purification. The carbon cloth was activated by $\mathrm{KMnO}_{4}$ according to previous literature [31]. The Ni-Co-Mo-P nanoarrays grown on carbon cloth were prepared via a two-step hydrothermal method and phosphorization treatment. Typically, $1 \mathrm{mmol}$ of nickel nitrate hexahydrate $\left(\mathrm{Ni}\left(\mathrm{NO}_{3}\right)_{2} \cdot 6 \mathrm{H}_{2} \mathrm{O}\right), 2 \mathrm{mmol}$ of cobaltous nitrate hexahydrate $\left(\mathrm{Co}\left(\mathrm{NO}_{3}\right)_{2} \cdot 6 \mathrm{H}_{2} \mathrm{O}\right), 6 \mathrm{mmol}$ of ammonium fluoride $\left(\mathrm{NH}_{4} \mathrm{~F}\right)$ and $15 \mathrm{mmol}$ urea were dissolved into $70 \mathrm{~mL}$ of deionized water to form a homogeneous solution. The solution and a piece of carbon cloth $(1 \mathrm{~cm} \times 2 \mathrm{~cm})$ were transferred to a 100-mL Teflon lined stainless steel autoclave (internal diameter of $42 \mathrm{~mm}$ with a height of $72 \mathrm{~mm}$ ) and heated and held at $120^{\circ} \mathrm{C}$ for $3 \mathrm{~h}$. After the reaction, the carbon cloth was taken out and rinsed with ethanol and deionized (DI) water several times and dried at $60^{\circ} \mathrm{C}$ under vacuum overnight. The obtained carbon cloth with the NiCo precursor was further immersed into a $40 \mathrm{~mL}$ solution containing $0.72 \mathrm{mmol}$ of $\mathrm{Ni}\left(\mathrm{NO}_{3}\right)_{2} \cdot 6 \mathrm{H}_{2} \mathrm{O}$ and $0.72 \mathrm{mmol}$ of sodium molybdat dihydrat $\left(\mathrm{Na}_{2} \mathrm{MoO}_{4} \cdot 2 \mathrm{H}_{2} \mathrm{O}\right)$ and reacted at $120^{\circ} \mathrm{C}$ for $6 \mathrm{~h}$ to prepare $\mathrm{Ni}-\mathrm{Co}-\mathrm{Mo}-\mathrm{O}$ nanoarrays. $\mathrm{Ni}$ Co-Mo-P nanoarrays were obtained by annealing Ni-Co-Mo-O nanoarrays and $300 \mathrm{mg}$ sodium hypophosphite $\left(\mathrm{NaH}_{2} \mathrm{PO}_{2}\right)$ powders together at $400^{\circ} \mathrm{C}$ for $2 \mathrm{~h}$ with a heating rate of $2^{\circ} \mathrm{C} \mathrm{min}{ }^{-1}$ in Ar atmosphere and then cooling to room temperature under the continuous flowing argon. NiCoP nanoarrays were obtained via a direct phosphorization treatment of the $\mathrm{NiCo}$ precursor. For comparison, the $\mathrm{W}$ element, which is in the same main group with $\mathrm{Mo}$, was also introduced into $\mathrm{NiCoP}$ nanoarrays using sodium tungstate dihydrate $\left(\mathrm{Na}_{2} \mathrm{WO}_{4} \cdot 2 \mathrm{H}_{2} \mathrm{O}\right)$ via the same process. The mass loadings of $\mathrm{NiCoP}, \mathrm{Ni}-\mathrm{Co}-\mathrm{Mo}-\mathrm{P}$ and $\mathrm{Ni}-\mathrm{Co}-\mathrm{W}-\mathrm{P}$ nanoarrays were about $2.5,5.8$ and $4.2 \mathrm{mg} \mathrm{cm}^{-2}$, respectively.

\section{Material characterizations}

The morphology and microstructure of the samples were recorded on a scanning electron microscope (SEM, SU-8010) and a transmission electron microscope (TEM, Tecnai G2 F20) equipped with an energy-dispersive X-ray spectrometer (EDS) operated at $200 \mathrm{kV}$. The surface areas of samples were estimated using Brunauer-Emmett-Teller (BET, Micro metrics ASAP 2460). Phase characterizations and crystal structures were investigated by X-ray diffraction (XRD, Rigaku, D/Ultima IV, $\lambda$ $=1.5418 \AA$ ) with $\mathrm{Cu} \mathrm{Ka}$ radiation. The evolution of the composition and surface valence states of the as-prepared samples were conducted by X-ray photoelectron spectroscopy (XPS, Thermo Fisher Scientific, Kalpha). Kelvin probe force microscopy (KPFM, NanoIR2-fs) was conducted to measure the surface potential and work function (WF).

\section{Electrochemical characterizations}

Electrochemical properties of the electrodes were tested in a three-electrode system with $3 \mathrm{~mol} \mathrm{~L}^{-1}$ potassium hydroxide $(\mathrm{KOH})$ as the electrolyte, in which the as-prepared sample, $\mathrm{Hg}$ / $\mathrm{HgO}$ electrode and a Pt foil $(1 \mathrm{~cm} \times 1 \mathrm{~cm})$ acted as the working electrode, reference electrode and counter electrode, respectively. Cyclic voltammetry (CV), galvanostatic charge-discharge (GCD), and electrochemical impedance spectroscopy (EIS) in the frequency range from $100 \mathrm{kHz}$ to $0.01 \mathrm{~Hz}$ with an alternating current amplitude of $5 \mathrm{mV}$ at the open circuit potential were tested on a CHI 760E electrochemical workstation. The longterm cycling performance was obtained by an SC testing instrument (LAND CT3001A). Areal capacity $\left(C_{\mathrm{a}}, \mathrm{C} \mathrm{cm}^{-2}\right)$ and gravimetric capacity $\left(C_{g}, \mathrm{C} \mathrm{g}^{-1}\right)$ were calculated from the GCD curves using the following equations:

$C_{\mathrm{a}}=I \Delta t / S$,

$C_{\mathrm{g}}=I \Delta t / m$,

where $I$ is the discharge current $(\mathrm{mA}), \Delta t$ is the discharge time (s), $S$ is the geometric area of the electrode, and $m$ is the mass of the active material $(\mathrm{mg})$.

\section{Fabrication of HSC devices}

The HSC devices were assembled by the as-prepared samples and $\mathrm{AC}$ electrode using $3 \mathrm{~mol} \mathrm{~L}^{-1} \mathrm{KOH}$ as the electrolyte. A glass fiber filter (Whatman, Grade GF/D) with unique pore structure, high acid-alkali resistance, high strength and good ion permeability was used as the separator and dipped into $3 \mathrm{~mol} \mathrm{~L}^{-1} \mathrm{KOH}$ overnight. For the synthesis of the AC electrode, $\mathrm{AC}$, acetylene black and polyvinylidene fluoride (PVDF) were mixed in a mass ratio of 80:10:10 in $N$-methyl-2-pyrrolidone 
(NMP) to form a slurry, which was then pasted on the carbon cloth $(1 \mathrm{~cm} \times 1 \mathrm{~cm})$ and dried at $60^{\circ} \mathrm{C}$ under vacuum overnight. Before the synthesis of the AC electrode, the mass of AC was determined by the following equation according to charge balance:

$\frac{m_{+}}{m_{-}}=\frac{C_{-} \times V_{-}}{Q_{+}}$,

where $Q_{+}, C_{-}$, and $V_{-}$are the specific capacity of the positive electrode, the specific capacitance and potential window of the AC electrode, respectively. The mass ratio of $\mathrm{Ni}-\mathrm{Co}-\mathrm{Mo}-\mathrm{P}$ nanoarrays to AC was calculated to be approximately 0.18 .

The flexible all-solid-state HSC device was assembled through the similar procedure using polyvinyl alcohol (PVA)/KOH as the electrolyte. The PVA/KOH gel electrolyte was prepared as following: $2.0 \mathrm{~g}$ of PVA was first dissolved into $20 \mathrm{~mL}$ of deionized water and stirred continuously at $80^{\circ} \mathrm{C}$ for $1 \mathrm{~h}$. Then, $1.68 \mathrm{~g}$ of $\mathrm{KOH}$ dissolved in $10 \mathrm{~mL}$ DI water was dropwise added into the transparent polymer solution. After stirring at $80^{\circ} \mathrm{C}$ for another $1 \mathrm{~h}$, the clear PVA/KOH was obtained as the gel electrolyte. Specific capacity $(C)$, energy density $(E)$ and power density $(P)$ of the HSC device were calculated based the following equations:

$$
\begin{aligned}
& C=\frac{I \times \Delta t}{M}, \\
& E=\frac{I \int V \mathrm{~d} t}{M \times 3.6}, \\
& P=\frac{E \times 3600}{\Delta t},
\end{aligned}
$$

where $M$ is the total mass of the positive and negative electrodes (mg), and $V$ is the potential window of the discharge process.

\section{Density functional theory calculations}

Density functional theory (DFT) calculations were performed by the Vienna $A b$ initio Simulation Package (VASP). Projector augmented wave and Perdew-Burke-Ernzerhof (PAW-PBE) functionals were used to describe the exchange-correlation effects between electrons. In this work, we considered that $\mathrm{NiCoP}$ formed heterojunctions with NiMoP in Ni-Co-Mo-P nanoarrays and $\mathrm{WP}_{2}$ in $\mathrm{Ni}-\mathrm{Co}-\mathrm{W}-\mathrm{P}$ nanoarrays, respectively. The (111) plane of NiCoP was selected to simulate the surface of the material. In order to avoid interactions, a vacuum zone of $12 \AA$ was added. As for the two heterojunctions, they were modelled by the (111) planes of both NiCoP and NiMoP, with the (111) plane of NiCoP binding to the (201) plane of $\mathrm{WP}_{2}$. All structures were totally relaxed under energy convergence tolerance of $1 \times 10^{-5} \mathrm{eV}$ and stress lower than $5 \times 10^{-2} \mathrm{eV} \mathrm{A}^{-1}$ with the Monkhorst Brillouin sampling mesh of $3 \times 3 \times 1$. The plane wave energy cutoff was set to be $500 \mathrm{eV}$ for all calculations. The density of states and projected density of states were calculated on a denser Brillouin zone sampling of $6 \times 6 \times 2$.

\section{RESULTS AND DISCUSSION}

The preparation procedures of Ni-Co-Mo-P and Ni-Co-W-P nanoarrays are illustrated in Fig. 1a and Fig. S1, respectively. The $\mathrm{Ni}$-Co precursor nanoarrays were grown on the carbon cloth via a hydrothermal method, followed by the introduction of Mo element through the second hydrothermal process to prepare $\mathrm{Ni}-\mathrm{Co}-\mathrm{Mo}-\mathrm{O}$ nanoarrays. The Ni-Co-Mo-P nanoarrays were finally obtained by the phosphorization treatment with
$\mathrm{NaH}_{2} \mathrm{PO}_{2}$ as the $\mathrm{P}$ source. As shown in Fig. S2, the as-prepared $\mathrm{NiCoP}, \mathrm{Ni}-\mathrm{Co}-\mathrm{Mo}-\mathrm{P}$ and $\mathrm{Ni}-\mathrm{Co}-\mathrm{W}-\mathrm{P}$ nanoarrays are grown uniformly on the carbon fiber. The NiCoP nanoarrays exhibit a smooth nanowire-nanoflake morphology, in which the crosslinked nanowires with a diameter of $\sim 100 \mathrm{~nm}$ grow at the edge of nanoflakes (Fig. S3). After the incorporation of Mo, the nanowire-nanoflake structure is well retained except some subtle changes (Fig. 1b). Ni-Co-Mo-P nanoflakes are covered with many nanosheets and the nanowires consist of several regularly distributed smooth interconnected nanosheets (Fig. 1c). The thickness of nanosheets is in the range of $30-40 \mathrm{~nm}$ and the diameter of nanowires increases to $\sim 200 \mathrm{~nm}$. This 3D open nanostructure can not only ensure easy contact between the electrode and electrolyte, but also provide large space to facilitate the electron transfer and ion diffusion. The TEM images confirm the nanowire-nanoflake structure of Ni-Co-Mo-P nanoarrays, in which the nanowires consist of ultrathin and smooth nanosheets formed by interconnected nanoparticles (Fig. 1d and Fig. S4). Furthermore, the lattice spacings of 0.23 and $0.22 \mathrm{~nm}$ in the high-resolution TEM (HRTEM) image (Fig. 1e) correspond to the (111) planes of NiMoP and $\mathrm{NiCoP}$, respectively. In addition, there is an interface between two-phase lattice fringes, indicating the formation of the $\mathrm{NiCoP} / \mathrm{NiMoP}$ heterostructure. The polycrystalline characteristic of Ni-Co-Mo-P nanoarrays can be observed via the selected area electron diffraction (SAED) pattern in Fig. 1f. Note that the diffraction rings are respectively assigned to the (111) and (201) planes of NiCoP and the (211) plane of NiMoP. EDS images (Fig. 1g) show the homogeneous distribution of $\mathrm{Ni}, \mathrm{Co}$, Mo and $\mathrm{P}$ elements in Ni-Co-Mo-P nanoarrays, confirming the successful introduction of Mo element into NiCoP. As a comparison, the morphology and phase of NiCoP also change after introducing $\mathrm{W}$ element. From the SEM (Fig. S5) and TEM images (Fig. S6a), a large number of nanoparticles grow on the nanoarrays to form a tough surface. Different from the Ni-Co-Mo-P nanoarrays, there are many nanotubes with a diameter of approximately $190 \mathrm{~nm}$ for Ni-CoW-P nanoarrays, which are derived from nanowires during annealing treatment due to the nanoscale Kirkendall effect $[32,33]$. Specially, the Ni-Co-W-P nanoarrays display a hollow structure (Fig. S6b), leading to a lower mass loading than that of $\mathrm{Ni}$-Co-Mo-P nanowires. Three different lattice fringes can be observed in the HRTEM image of Ni-Co-W-P nanoarrays (Fig. S6c). The measured lattice spacings of $0.268,0.420$ and $0.219 \mathrm{~nm}$ belong to the $(201)$ and $(-201)$ planes of $\mathrm{WP}_{2}$ and (111) plane of NiCoP, respectively. Additionally, the SAED patterns of Ni-Co-W-P nanoarrays also demonstrate polycrystalline characteristics (Fig. S6d), corresponding to the (210) and (300) planes of NiCoP and (201) plane of $\mathrm{WP}_{2}$, respectively. EDS mapping confirms the presence of $\mathrm{Ni}, \mathrm{Co}, \mathrm{W}$, and $\mathrm{P}$ elements in Ni-Co-W-P nanoarrays (Fig. S7). The specific surface areas of the NiCoP, Ni-Co-Mo-P and Ni-Co-W-P electrodes were analyzed by the nitrogen adsorption-desorption isotherms and are shown in Fig. S8. After introducing Mo or W, both $\mathrm{Ni}-\mathrm{Co}-\mathrm{Mo}-\mathrm{P}$ and Ni-Co-W-P nanoarrays exhibit increased specific surface areas. The $\mathrm{Ni}-\mathrm{Co}-\mathrm{Mo}-\mathrm{P}$ nanoarrays possess a specific surface area of $6.09 \mathrm{~m}^{2} \mathrm{~g}^{-1}$, which is higher than that of $\mathrm{Ni}$-Co-W-P $\left(5.373 \mathrm{~m}^{2} \mathrm{~g}^{-1}\right)$ and $\mathrm{NiCoP}\left(3.864 \mathrm{~m}^{2} \mathrm{~g}^{-1}\right)$ nanoarrays, due to the abundant nanosheets on the nanoarrays. Benefiting from the larger specific surface area, the Ni-Co-Mo-P nanoarrays can provide abundant active sites for redox action and fast pathway for electrolyte ion transport. 

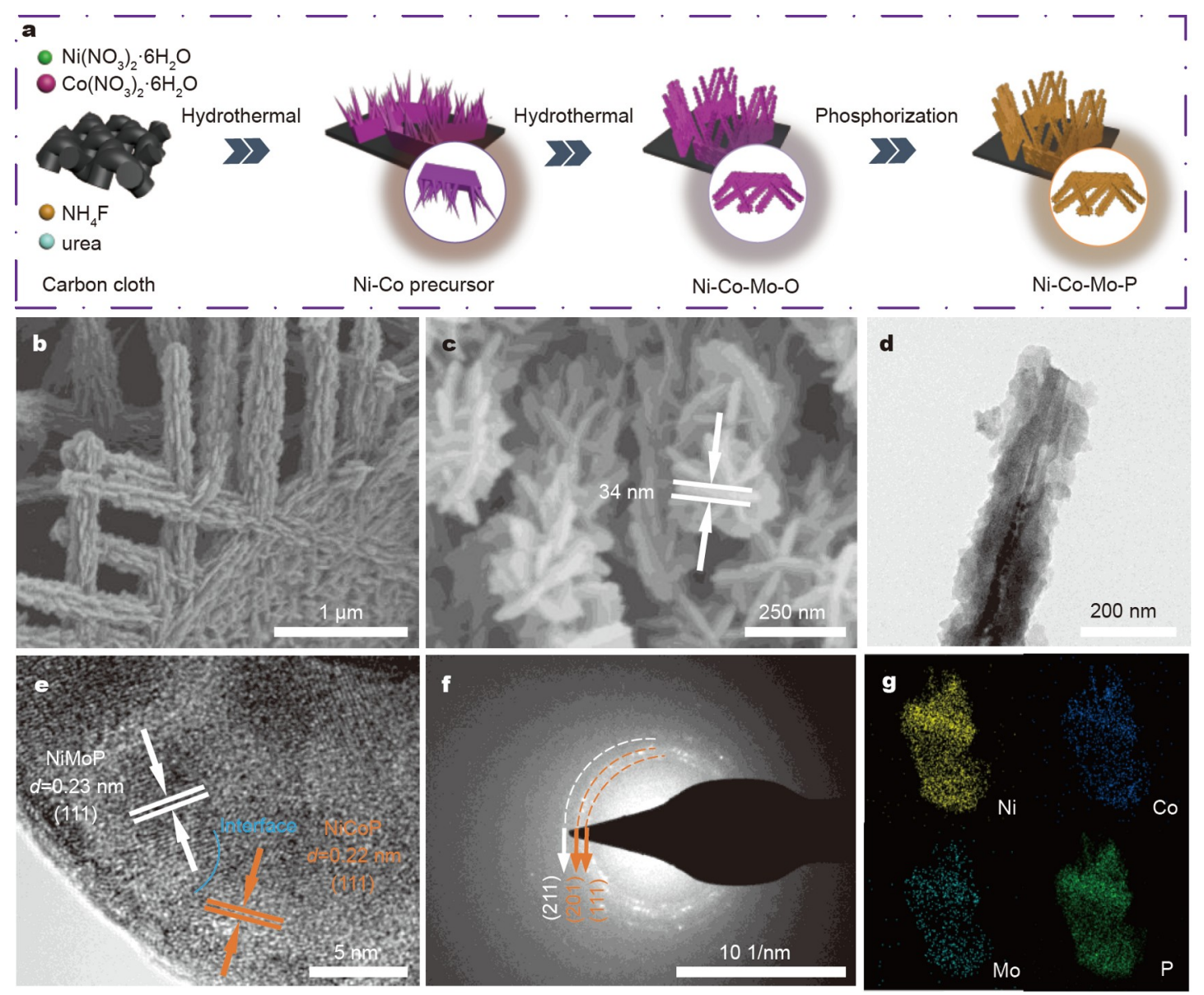

Figure 1 (a) Schematic illustration for the fabrication of Ni-Co-Mo-P nanoarrays on carbon cloth. (b, c) SEM images at different magnifications, (d, e) TEM and HRTEM images, (f) corresponding SAED pattern and (g) EDS mapping images of Ni-Co-Mo-P nanoarrays.

XRD patterns of the NiCoP, Ni-Co-Mo-P and Ni-Co-W-P samples are compared in Fig. 2a. A broad signal at around $25^{\circ}$ in all samples can be assigned to the carbon cloth substrate. In addition, all the samples display typical diffraction peaks indexed to NiCoP (JCPDS No. 71-2336) [25], where the peaks at $41.0^{\circ}$ and $55.3^{\circ}$ correspond to the (111) and (211) planes, respectively. For the Ni-Co-Mo-P nanoarrays, the peaks at $43.5^{\circ}$ and $63.5^{\circ}$ originate from the (201) and (220) crystal planes of NiMoP (JCPDS No. 31-0873) [34]. The Ni-Co-W-P nanoarrays show four characteristic peaks at $33.1^{\circ}, 36.3^{\circ}, 37.7^{\circ}$ and $66.5^{\circ}$, which are attributed to the corresponding (201), (111), (-112) and (200) lattice planes of $\mathrm{WP}_{2}$ (JCPDS No. 76-2365) [35]. The XRD results further demonstrate the successful incorporation of Mo or $\mathrm{W}$ elements into $\mathrm{NiCoP}$ and the formation of heterostructures.

The XPS survey spectra shown in Fig. S9 show the main elements of the three electrodes. In the high-resolution spectra of $\mathrm{Ni} 2 \mathrm{p}_{3 / 2}$ (Fig. 2b), two peaks located at 853.9 and $857.5 \mathrm{eV}$ for $\mathrm{NiCoP}$ are attributed to $\mathrm{Ni}^{2+}$ and $\mathrm{Ni}^{3+}$ and one shakeup satellite peak (Sat.) derives from multielectron excitation [36]. For the high-resolution Co $2 \mathrm{p}_{3 / 2}$ spectrum of $\mathrm{NiCoP}$, two peaks at 779.1 and $782.5 \mathrm{eV}$ belonging to $\mathrm{Co}^{3+}$ and $\mathrm{Co}^{2+}$ and a shakeup satellite peak due to the octahedral coordination of $\mathrm{Co}^{2+}$ can be observed [37]. After the incorporation of Mo or W, both Ni $2 \mathrm{p}_{3 / 2}$ and Co $2 \mathrm{p}_{3 / 2}$ peaks shift to higher binding energies compared with those for $\mathrm{NiCoP}$, demonstrating that the strong interaction at the heterointerface causes a charge redistribution. Moreover, the conversion of $\mathrm{Ni}^{3+}$ to $\mathrm{Ni}^{2+}$ and $\mathrm{Co}^{2+}$ to $\mathrm{Co}^{3+}$ indicates a charge transfer from $\mathrm{Co}$ ions to $\mathrm{Ni}$ ions due to the incorporation of high-valence Mo or W elements [38]. For the P 2p spectrum of Ni-Co-Mo-P nanoarrays, two peaks located at 134.9 and $130.3 \mathrm{eV}$ can be ascribed to oxidized phosphides on the surface (P-O) and metal-P bond, respectively [39]. In the Mo 3d spectrum of $\mathrm{Ni}-\mathrm{Co}-\mathrm{Mo}-\mathrm{P}$ nanoarrays (Fig. 2e), two characteristic peaks at 234.4 and $235.8 \mathrm{eV}$ come from $\mathrm{Mo}^{6+}$ and the signals at 230.9 and $232.9 \mathrm{eV}$ are attributed to $\mathrm{Mo}^{4+}[40,41]$. Mo element exhibits various valence states and low-oxidation-state Mo is believed to be rich in the redox action species and contributes to the electrochemical property [42]. As for the W 4 f spectrum of Ni-Co-W-P nanoarrays (Fig. 2f), peaks at 35.7, 37.8 and $41.2 \mathrm{eV}$ are assigned to $\mathrm{W} 4 \mathrm{f}_{7 / 2}, \mathrm{~W} 4 \mathrm{f}_{5 / 2}$ and $\mathrm{W} 5 \mathrm{p}_{3 / 2}$, respectively. This result indicates that there is only $\mathrm{W}^{6+}$ in $\mathrm{Ni}-\mathrm{Co}-\mathrm{W}-\mathrm{P}$ nanoarrays, which is possibly attributed to the little effect of $\mathrm{P}$ on the electronic structure of $\mathrm{W}$ [43]. The XPS results display the various valence states of $\mathrm{Ni}$, Co and $\mathrm{Mo}$ in $\mathrm{Ni}-\mathrm{Co}-\mathrm{Mo}-\mathrm{P}$ nanoarrays which could benefit the generation of higher capacity.

As shown in Fig. 3a, a pair of obvious redox peaks can be found in $\mathrm{CV}$ curves of NiCoP, Ni-Co-Mo-P and Ni-Co-W-P electrodes, indicating their reversible faradaic behavior. Compared with $\mathrm{NiCoP}$, both oxidation and reduction peaks of $\mathrm{Ni}$ Co-Mo-P and Ni-Co-W-P nanoarrays display a positive shift, demonstrating the increased battery-type behavior after intro- 

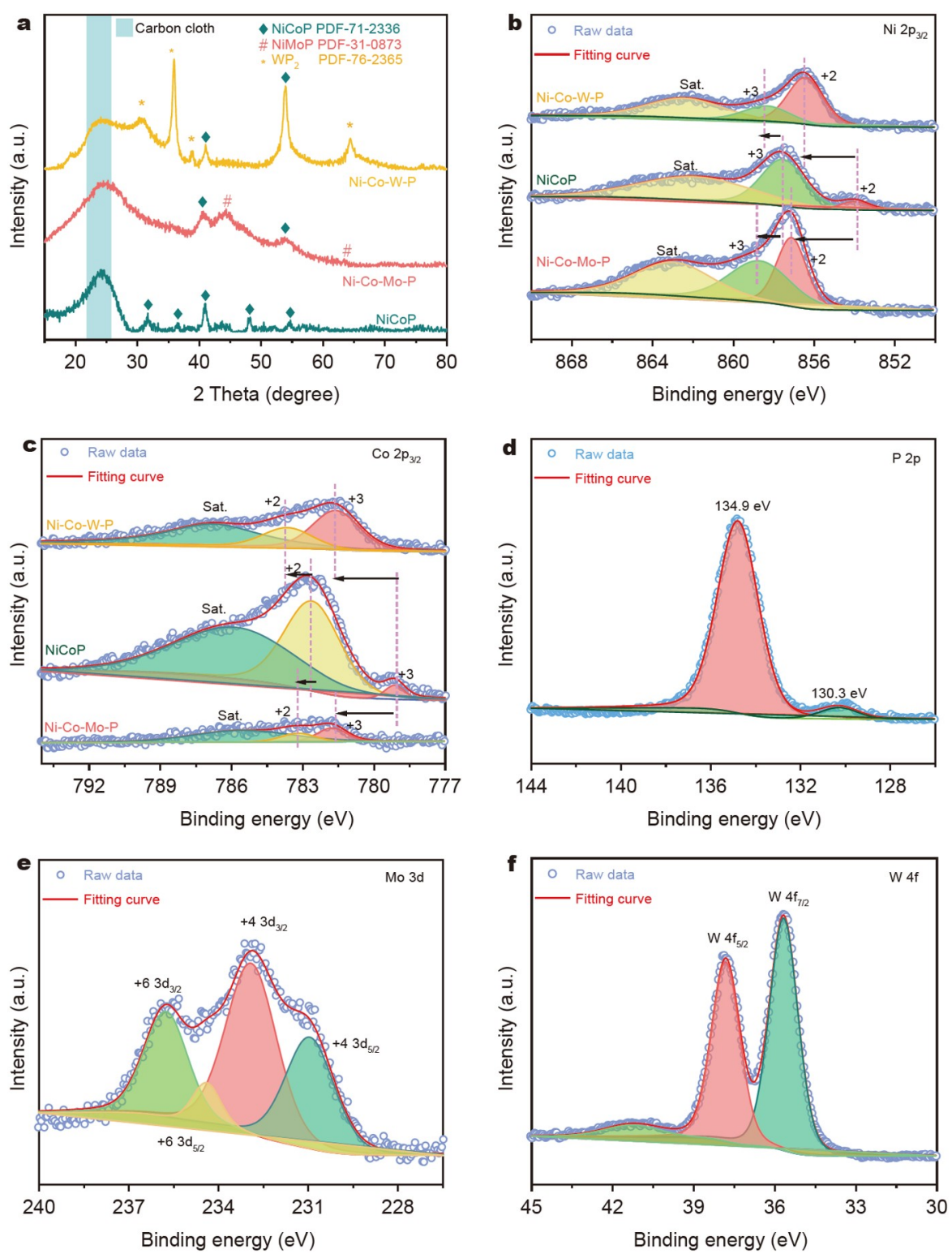

Figure 2 (a) XRD patterns of NiCoP, Ni-Co-Mo-P and Ni-Co-W-P nanoarrays. (b) XPS spectra of Ni 2p, (c) Co 2p, (d) P 2p, (e) Mo 3d of Ni-Co-Mo-P nanoarrays and (f) $\mathrm{W} 4 \mathrm{f}$ of Ni-Co-W-P nanoarrays.

ducing Mo or W. Obviously, the Ni-Co-Mo-P electrode provides the largest $\mathrm{CV}$ integral area among the three electrodes, suggesting its highest specific capacity. The $\mathrm{CV}$ curves at different scan rates from 5 to $25 \mathrm{mV} \mathrm{s}^{-1}$ for Ni-Co-Mo-P, NiCoP and NiCo-W-P electrodes were measured and are displayed in Fig. 3b and Fig. S10. With the increase of scan rate, the shift of redox peaks could be observed due to the polarization effects at high scan rates. The reaction kinetics can be analyzed from the $\mathrm{CV}$ curves at low scan rates (Fig. S11a), in which the relationship between the peak current $(i)$ and scan rate $(v)$ can be described by the following equation $[44,45]$ :

$i=a v^{b}$,

where $a$ and $b$ are adjustable parameters. For the ideal diffusioncontrolled behavior, $b=0.5$, while $b=1$ represents the capacitive behavior. The $b$ values of NiCoP, Ni-Co-Mo-P and Ni-Co-W-P electrodes are $0.94,0.73$ and 0.85 , respectively, indicating the combination of capacitive and diffusion-controlled behavior in three samples (Fig. 3c). For the Ni-Co-Mo-P electrode, its smallest $b$ value suggests the highest proportion of diffusioncontrolled process in the electrochemical reaction. The ratio of capacitive $\left(k_{1} v\right)$ and diffusion-controlled $\left(k_{2} v^{1 / 2}\right)$ contribution can be approximately calculated based on the following equation $[46,47]$ :

$$
i(V)=k_{1} v+k_{2} v^{1 / 2} \text {. }
$$

The fitted CV curve of Ni-Co-Mo-P nanoarrays at a scan rate of $0.5 \mathrm{mV} \mathrm{s}^{-1}$ is shown in Fig. S11b, in which the shadow area represents the capacitive contribution (67\%). As shown in Fig. 3d, the diffusion-controlled contribution of the Ni-Co-Mo$\mathrm{P}$ electrode is higher than that of the Ni-Co-W-P electrode at different scan rates, consistent with the results of $b$ value. With increasing scan rate, the capacitive contribution in the Ni-CoMo-P electrode increases from $31 \%$ to $80 \%$, indicating that the electrochemical behavior of the Ni-Co-Mo-P electrode is mainly dominated by the capacitive process at high scan rates. The 

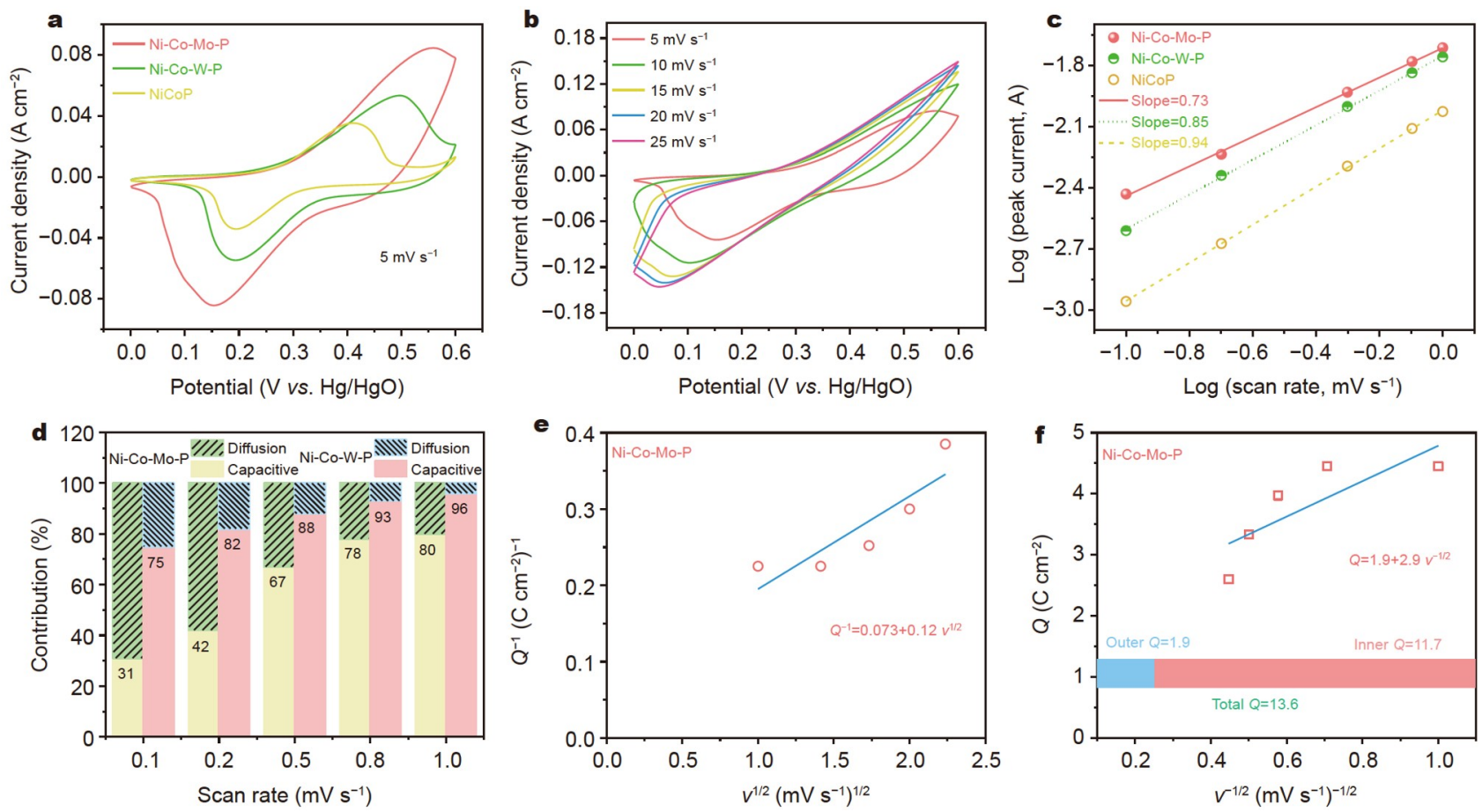

Figure 3 (a) $\mathrm{CV}$ curves of the three electrodes at $5 \mathrm{mV} \mathrm{s}^{-1}$. (b) $\mathrm{CV}$ curves of the Ni-Co-Mo-P electrode at different scan rates. (c) $b$-values of the three electrodes. (d) The contribution proportions in the Ni-Co-Mo-P and Ni-Co-W-P electrodes at various scan rates. (e) Plot of $Q^{-1}$ against $v^{1 / 2}$. (f) Plot of $Q$ against $v^{-1 / 2}$.

origin of stored charge can be further studied by Trasatti analysis. For an electrode, the stored total charge $\left(Q_{\mathrm{t}}\right)$ includes inner surface charge $\left(Q_{\mathrm{i}}\right)$ and outer surface charge $\left(Q_{\mathrm{o}}\right)$. The former is controlled by the diffusion process, while the later comes from the capacitive-controlled behavior and is related to the direct accessible surface. $Q_{t}, Q_{i}$ and $Q_{0}$ can be evaluated according to the following equations [48-50]:

$\mathrm{Q}(v)^{-1}=Q_{\mathrm{t}}{ }^{-1}+k v^{1 / 2}$,

$Q(v)=Q_{\mathrm{o}}+k v^{-1 / 2}$,

where $Q(v)$ is the stored charge at a fix scan rate and $v$ is the san rate. $Q(v)$ can be calculated from the integral area of $\mathrm{CV}$ curves at different scan rates. When $v=0$, the intercept of the linear plot of $Q(v)^{-1}$ against $v^{1 / 2}$ stands for $Q_{\mathrm{t}}^{-1}$, while $v=\infty$, the intercept of the linear plot of $Q(v)$ against $v^{-1 / 2}$ represents $Q_{0}$. As shown in Fig. $3 \mathrm{e}, \mathrm{f}$ and Fig. S12, the total charge that can be stored in the $\mathrm{Ni}-\mathrm{Co}-\mathrm{Mo}-\mathrm{P}$ electrode is found to be $13.6 \mathrm{C} \mathrm{cm}^{-2}$, higher than that of the $\mathrm{NiCoP}$ counterpart $\left(1.35 \mathrm{C} \mathrm{cm}^{-2}\right)$. Moreover, the $Q_{i}$ of the Ni-Co-Mo-P electrode accounts for approximately $86 \%$, much higher than that of $\mathrm{NiCoP}(20 \%)$. The $\mathrm{Ni}$-Co-W-P electrode also exhibits higher $Q_{\mathrm{i}}$ than that of $\mathrm{NiCoP}$ (Fig. S12). The higher ratio of $Q_{i}$ in the Ni-Co-Mo-P electrode indicates that most active sites exist in the inner surface and further confirms that the reaction kinetics is a diffusion-controlled process rather than capacitive process. Combining the above analysis, introducing high-valence elements into NiCoP nanoarrays could enhance the diffusion-controlled behavior and store more charges through adsorption/desorption process.

The GCD curves of NiCoP, Ni-Co-Mo-P and Ni-Co-W-P electrodes at a current density of $2 \mathrm{~mA} \mathrm{~cm}^{-2}$ are presented and compared in Fig. 4a. All curves show an obvious charge/discharge platform, demonstrating their battery-like behavior, which is consistent with the above CV curves. The Ni-Co-Mo-P electrode possesses the longest discharge time and delivers the highest capacity of $4.08 \mathrm{C} \mathrm{cm}^{-2}\left(703 \mathrm{C} \mathrm{g}^{-1}\right)$ among the three electrodes due to the various redox reaction species and high specific surface area that further increases the electrochemical activity and available sites. When the current density increases from 2 to $30 \mathrm{~mA} \mathrm{~cm}^{-2}$, the GCD curves are almost symmetric, indicating the high reversibility of the $\mathrm{Ni}-\mathrm{Co}-\mathrm{Mo}-\mathrm{P}$ electrode (Fig. 4b). Based on the GCD curves in Fig. S13, the rate capability is shown in Fig. 4c. Clearly, the Ni-Co-Mo-P electrode retains a superior rate performance and exhibits a high capacity retention of $80 \%$ even at a high current density of $30 \mathrm{~mA} \mathrm{~cm}^{-2}$, which could be attributed to the enhanced conductivity after the introduction of Mo. The Nyquist plots consist of a semi-circle in the high-frequency region and a straight line in the low-frequency region (Fig. $4 \mathrm{~d}$ ). The intercept of the semi-circle with the real axis represents the solution resistance $\left(R_{\mathrm{S}}\right)$. The diameter of semi-circle represents the charge-transfer resistance $\left(R_{\mathrm{ct}}\right)$, related to the charge transfer at the interface of electrode and electrolyte. The slope of the line demonstrates Warburg resistance $\left(Z_{\mathrm{W}}\right)$ corresponding to ion diffusion. The fitting circuit diagram and fitting results of the three electrodes are shown in Fig. S14 and Table S1, respectively. The Ni-Co-Mo-P electrode exhibits lower $R_{\mathrm{S}}(1.46 \Omega)$ and $R_{\mathrm{ct}}(0.015 \Omega)$ than other two electrodes, indicating the highest electrical conductivity and fastest charge transfer after incorporating Mo element. Bode phase angle plots of the NiCoP, Ni-Co-W-P and Ni-Co-Mo-P electrodes are shown in Fig. S15. The Ni-Co-Mo-P electrode exhibits the lowest phase angle of $-73^{\circ}$, indicating its smallest diffusion resistance. In addition, the response time $(\tau)$ is calculated from the capacitive response frequency $(f)$ at a phase angle of $-45^{\circ}$. The Ni-Co-Mo-P electrode gives a small response time of $10 \mathrm{~s}$ (21 s for Ni-Co-W-P and $25 \mathrm{~s}$ for the NiCoP electrodes), sug- 

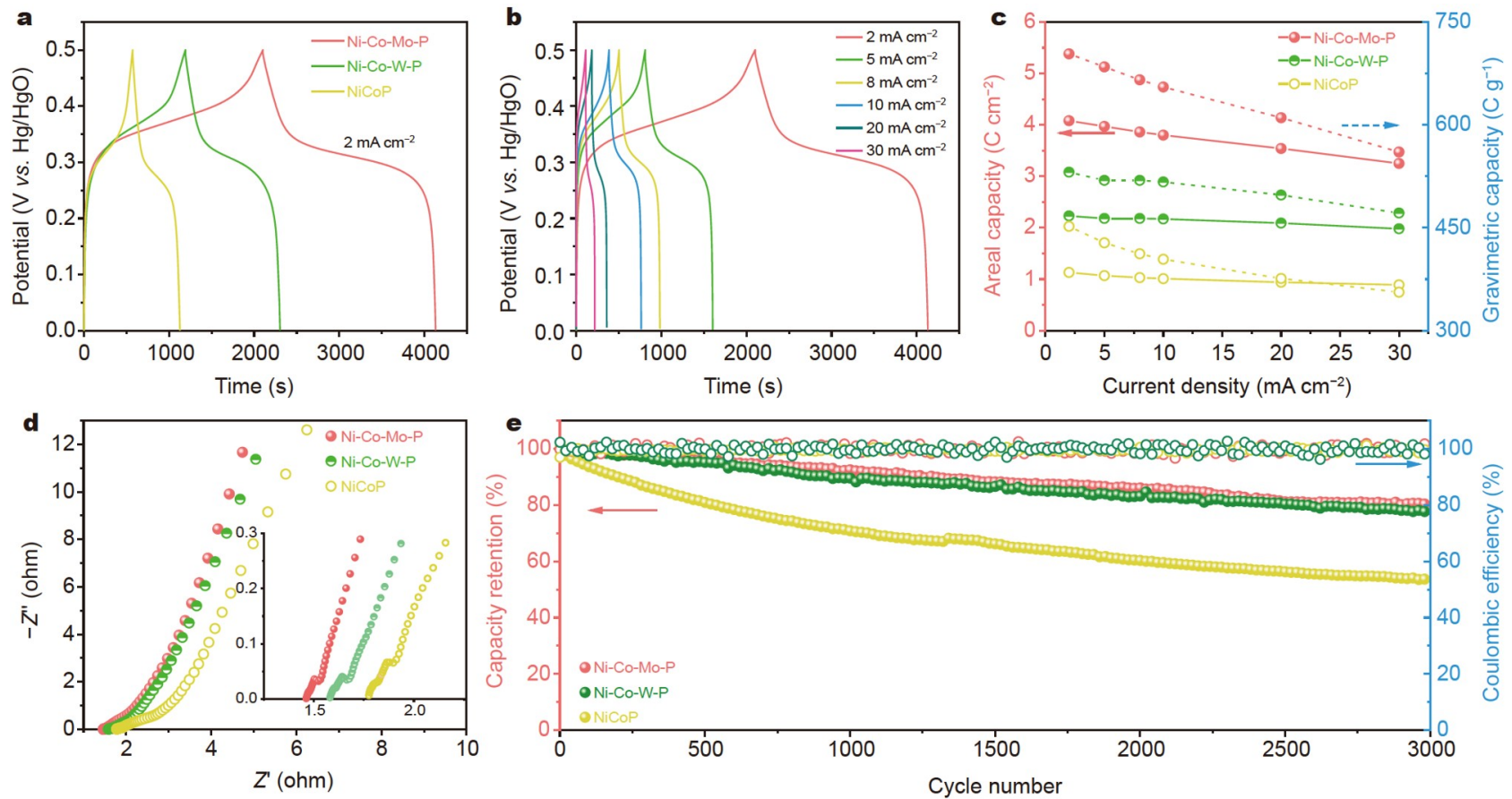

Figure 4 (a) Comparative GCD curves of the three electrodes at $2 \mathrm{~mA} \mathrm{~cm}^{-2}$. (b) GCD curves of the Ni-Co-Mo-P electrode at different current densities (c) Rate capability, (d) Nyquist plots and (e) cycling performance of the three electrodes.

gesting its fast charge/discharge characteristics. The cycling performance of the three electrodes was tested at $30 \mathrm{~mA} \mathrm{~cm}{ }^{-2}$ for 3000 cycles (Fig. 4e). The NiCoP electrode shows a fast capacity decay, while both Ni-Co-Mo-P and Ni-Co-W-P electrodes exhibit improved cycling stability and Coulombic efficiency due to the optimized nanostructure and enhanced electrical conductivity. After 3000 cycles, $80 \%$ capacity retention and $\sim 100 \%$ Coulombic efficiency were obtained in the Ni-CoMo-P electrode, higher than those of the NiCoP electrode (a capacity retention of $54 \%$ and Coulombic efficiency of $96 \%$ ). In order to verify the structural stability of electrodes, the XRD and SEM images of the three electrodes after cycling were tested and are shown in Fig. S16. The peaks at $19.5^{\circ}$ and $33.7^{\circ}$ are assigned to the $(001)$ and $(100)$ planes of $\mathrm{Ni}(\mathrm{OH})_{2}$, while the peak at $38^{\circ}$ belongs to the (011) plane of $\mathrm{Co}(\mathrm{OH})_{2}$ (Fig. S16a). Therefore, the capacity decay could be attributed to the formation of a hydroxide phase on the surface of electrodes. As shown in Fig. S16b, c, the morphologies of Ni-Co-Mo-P and Ni-Co-W-P nanoarrays remain well, while the $\mathrm{NiCoP}$ electrode suffers from obvious pulverization and agglomeration (Fig. S16d), indicating the enhanced structural stability after the incorporation of Mo/ $\mathrm{W}$ into NiCoP. The inferior structural stability leads to the fast capacity fade for the $\mathrm{NiCoP}$ electrode. In addition, small nanosheets formed on the electrode surface indicate the generation of metal hydroxide, which is in consistence with the $\mathrm{XRD}$ results. The improved cycling performance of Ni-Co-Mo-P nanoarrays can be benefited from interconnected nanosheets and abundant voids, which ensure the whole structural stability to prevent the pulverization of active materials and accommodate the volume changes during the electrochemical reactions. The Nyquist plots of the three electrodes after the cycling test are shown in Fig. S17a. Obviously, the Ni-Co-Mo-P electrode shows the largest slope of the line, indicating its lowest $Z_{\mathrm{w}}$ and fast ion diffusion even after 3000 cycles. Furthermore, the
$\mathrm{Ni}$-Co-Mo-P electrode displays the lowest phase angle of $-79^{\circ}$, indicating its smallest diffusion resistance (Fig. S17b). These results further confirm the excellent cycling performance of $\mathrm{Ni}$ Co-Mo-P nanoarrays.

The changes of surface potential and WF after the incorporation of high-valence elements were measured by KPFM at a nanometer scale. In the KPFM characterization, the WF of the sample $\left(\varphi_{\mathrm{s}}\right)$ is determined by the WF of the tip $\left(\varphi_{\mathrm{t}}\right)$ and the contact potential difference (CPD) between the tip and sample as described by the following equation [51,52]:

$\mathrm{CPD}=\left(\varphi_{\mathrm{s}}-\varphi_{\mathrm{t}}\right) / e$.

Compared with NiCoP, Ni-Co-Mo-P and Ni-Co-W-P nanoarrays display a rougher surface according to $3 \mathrm{D}$ topographical images (Fig. S18). The surface potential of NiCoP distributes uniformly as shown in Fig. 5a, while Ni-Co-Mo-P and $\mathrm{Ni}-\mathrm{Co}-\mathrm{W}$-P nanoarrays show an increased surface potential due to the increased thickness (Fig. 5c, e). Moreover, the CPD value of $\mathrm{NiCoP}$ along the line is $20 \mathrm{mV}$ (Fig. 5b), while the value becomes higher for Ni-Co-Mo-P nanoarrays ( $85 \mathrm{mV}$, Fig. $5 \mathrm{~d}$ ) and Ni-Co-W-P nanoarrays (42 $\mathrm{mV}$, Fig. $5 \mathrm{f}$ ), which could be caused by a generated internal electric field in the heterostructure after introducing Mo or W. This electric field will facilitate the charge transfer kinetics of the Ni-Co-Mo-P and NiCo-W-P electrodes. To further study the role of Mo or W elements on the enhancement of electrochemical properties, DFT calculations were performed. The crystal structures of NiCoP, $\mathrm{Ni}-\mathrm{Co}-\mathrm{Mo}-\mathrm{P}$ and $\mathrm{Ni}-\mathrm{Co}-\mathrm{W}-\mathrm{P}$ nanoarrays at different visual angles are shown in Fig. 5g, i, $\mathrm{k}$ and Fig. S18, in which the heterostructures form in Ni-Co-Mo-P and Ni-Co-W-P nanoarrays in comparison with $\mathrm{NiCoP}$ nanoarrays. The total densities of states (TDOS) of Ni-Co-Mo-P and Ni-Co-W-P nanoarrays exhibit obviously stronger charge densities around the Fermi level compared with that of the pristine NiCoP 
a

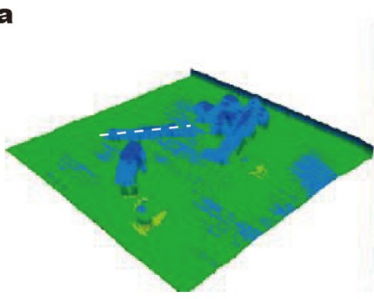

c

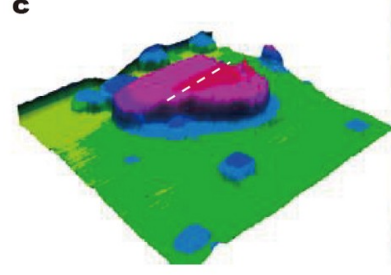

e

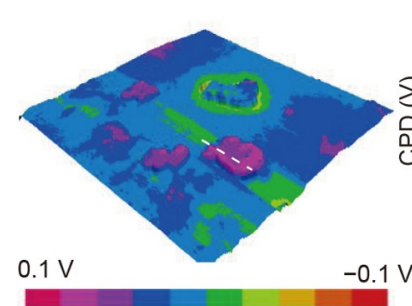

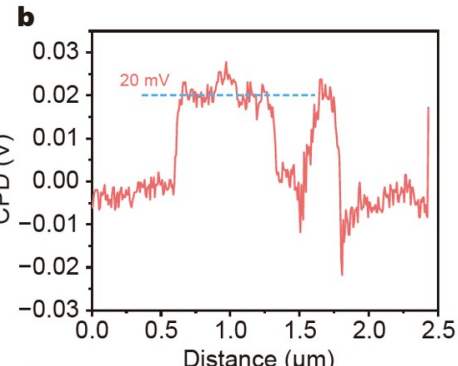
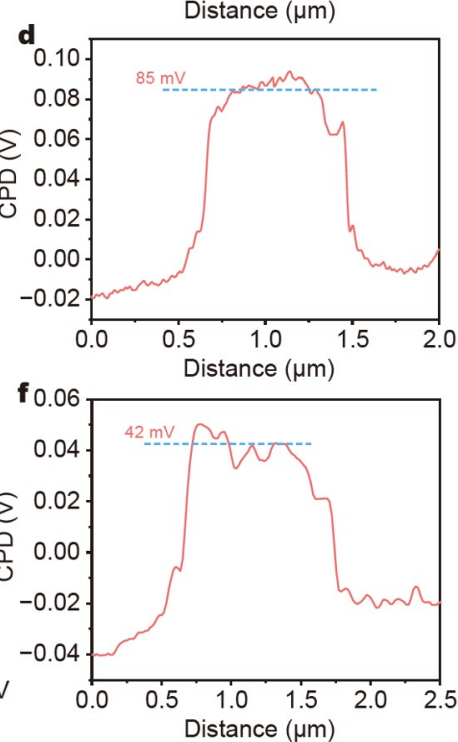

g

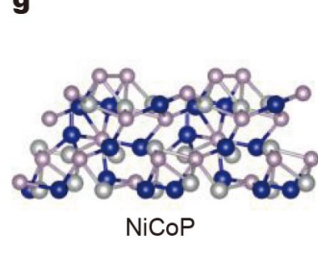

i

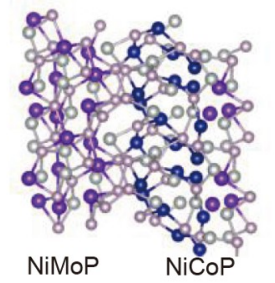

$\mathbf{k}$

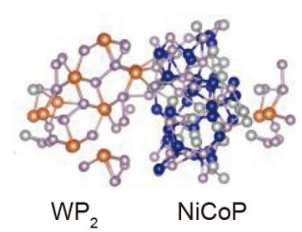

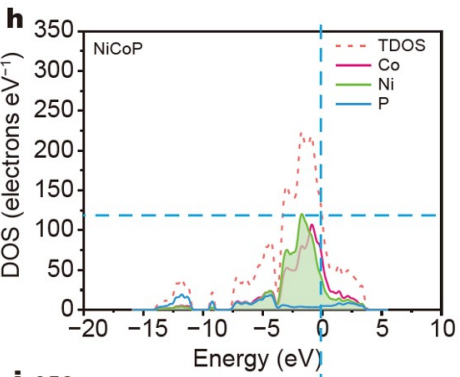

j 350 Energy (eV)
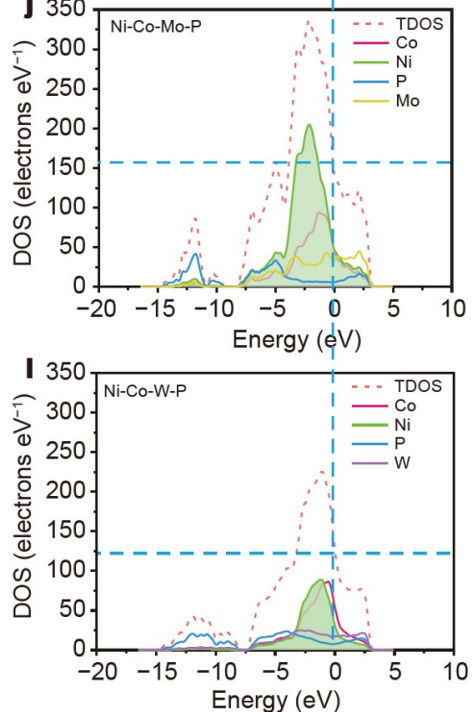

Figure 5 CPD images and corresponding line profiles for $(\mathrm{a}, \mathrm{b}) \mathrm{NiCoP},(\mathrm{c}, \mathrm{d}) \mathrm{Ni}$-Co-Mo-P nanoarrays and (e, f) Ni-Co-W-P nanoarrays. Crystal structures and total and partial densities of states for $(\mathrm{g}, \mathrm{h}) \mathrm{NiCoP},(\mathrm{i}, \mathrm{j}) \mathrm{Ni}-\mathrm{Co}-\mathrm{Mo}-\mathrm{P}$ nanoarrays and $(\mathrm{k}, \mathrm{l}) \mathrm{Ni}-\mathrm{Co}-\mathrm{W}-\mathrm{P}$ nanoarrays.

nanoarrays, demonstrating enhanced conductivity and faster electron transfer (Fig. 5h, $\mathrm{j}$ and $\mathrm{l}$ ) [53]. Moreover, no band gap near Fermi level exists in the three samples, representing the metallic characteristic of phosphides. Owing to the introduction of Mo, a new energy level originating from the Mo $3 \mathrm{~d}$ orbital appears near the Fermi level, which accelerates the electron transport. In addition, compared with NiCoP nanoarrays, the orbital of $\mathrm{Ni}$ for $\mathrm{Ni}$-Co-Mo-P nanoarrays has an enhanced density near the Fermi level, which could provide more charge carries for redox reactions. However, no impressive changes could be observed after $\mathrm{W}$ incorporation. Therefore, the introduction of Mo can modify the electronic structure and electron density of $\mathrm{Ni}$ and $\mathrm{Co}$ to increase the conductivity and accelerate the reaction kinetics during the electrochemical redox reaction, resulting in the best electrochemical properties of the $\mathrm{Ni}-\mathrm{Co}-$ Mo-P electrode.

Combined with the above electrochemical reaction mechanism analysis, the outstanding electrochemical properties of $\mathrm{Ni}$ Co-Mo-P nanoarrays can be attributed to the following points: (1) 3D open hetero-structured nanoarrays provide abundant active sites and accessible channels for the rapid electrolyte ion transfer as well as abundant voids for accommodating volume expansion during the cycling process, thus contributing to high capacity and long-life span. (2) The incorporation of Mo builds an internal electric field in the heterostructure and increases the intrinsic conductivity, which can induce the charge transfer and accelerate the reaction kinetics to improve the rate capability. (3) The different valence states of Mo offer rich redox reactions and establish synergetic effects with other components, resulting in the high electrochemical activity to obtain enhanced capacity.

An HSC was assembled by Ni-Co-Mo-P nanoarrays as the cathode and $\mathrm{AC}$ as the anode (denoted as Ni-Co-Mo-P//AC) to evaluate the practical application of the Ni-Co-Mo-P electrode (Fig. 6a). The characterizations and electrochemical properties of commercial AC are shown in Figs S19 and S20. As shown in Fig. 6b, the work potentials of AC and Ni-Co-Mo-P nanoarrays tested in a three-electrode system are $-1.0-0$ and $0-0.6 \mathrm{~V}$, respectively, indicating that the theoretical work potential of the $\mathrm{Ni}-\mathrm{Co}-\mathrm{Mo}-\mathrm{P} / / \mathrm{AC}$ device could reach up to $1.6 \mathrm{~V}$. To determine the maximum operating voltage of $\mathrm{Ni}-\mathrm{Co}-\mathrm{Mo}-\mathrm{P} / / \mathrm{AC}, \mathrm{CV}$ and GCD curves at various potential windows are recorded in Fig. $6 \mathrm{c}$, d. When the voltage increases to $1.7 \mathrm{~V}$, the CV curve shows a deformed shape and an asymmetric GCD curve can be observed due to the polarization effect and irreversible reaction. Therefore, the work potential of $\mathrm{Ni}-\mathrm{Co}-\mathrm{Mo}-\mathrm{P} / / \mathrm{AC}$ was determined as $0-1.6$ V. In Fig. 6e, the CV curves of Ni-Co-Mo-P//AC have no obvious distortion in a wide scan rate range from 10 to $100 \mathrm{mV} \mathrm{s}^{-1}$, indicating the good capacitive characteristic. Moreover, Ni-Co-Mo-P//AC shows the highly symmetric GCD curves, which demonstrates the high reversibility of electrochemical reactions (Fig. 6f). As a comparison, Ni-Co-W-P//AC was also assembled using $\mathrm{Ni}-\mathrm{Co}-\mathrm{W}-\mathrm{P}$ nanoarrays and $\mathrm{AC}$ as the positive and negative electrodes, respectively. The specific capacities of $\mathrm{Ni}-\mathrm{Co}-\mathrm{Mo}-\mathrm{P} / / \mathrm{AC}$ and $\mathrm{Ni}-\mathrm{Co}-\mathrm{W}-\mathrm{P} / / \mathrm{AC}$ can be calculated from GCD curves (Fig. $6 \mathrm{~g}$ and Fig. S21). Ni-Co-Mo$\mathrm{P} / / \mathrm{AC}$ delivers a specific capacity of $240 \mathrm{C} \mathrm{g}^{-1}$ at a current 
a

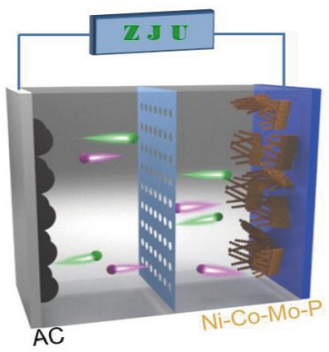$$
\text { d }
$$
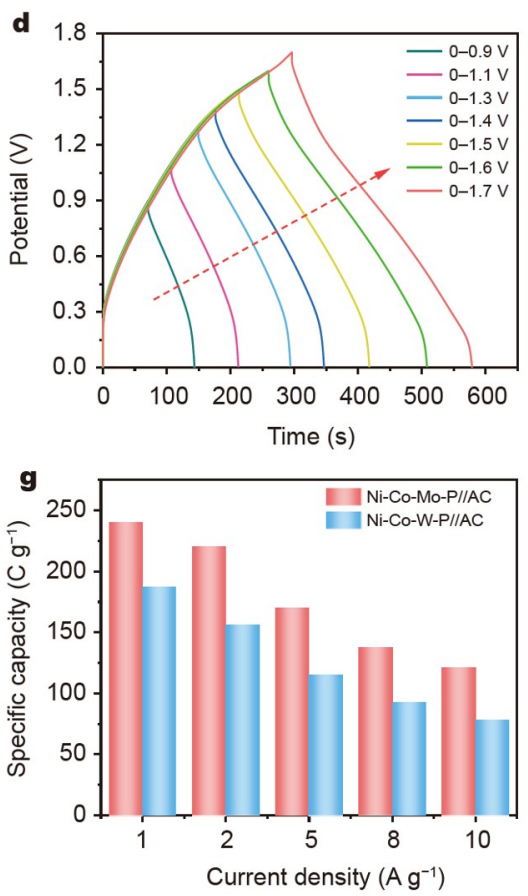
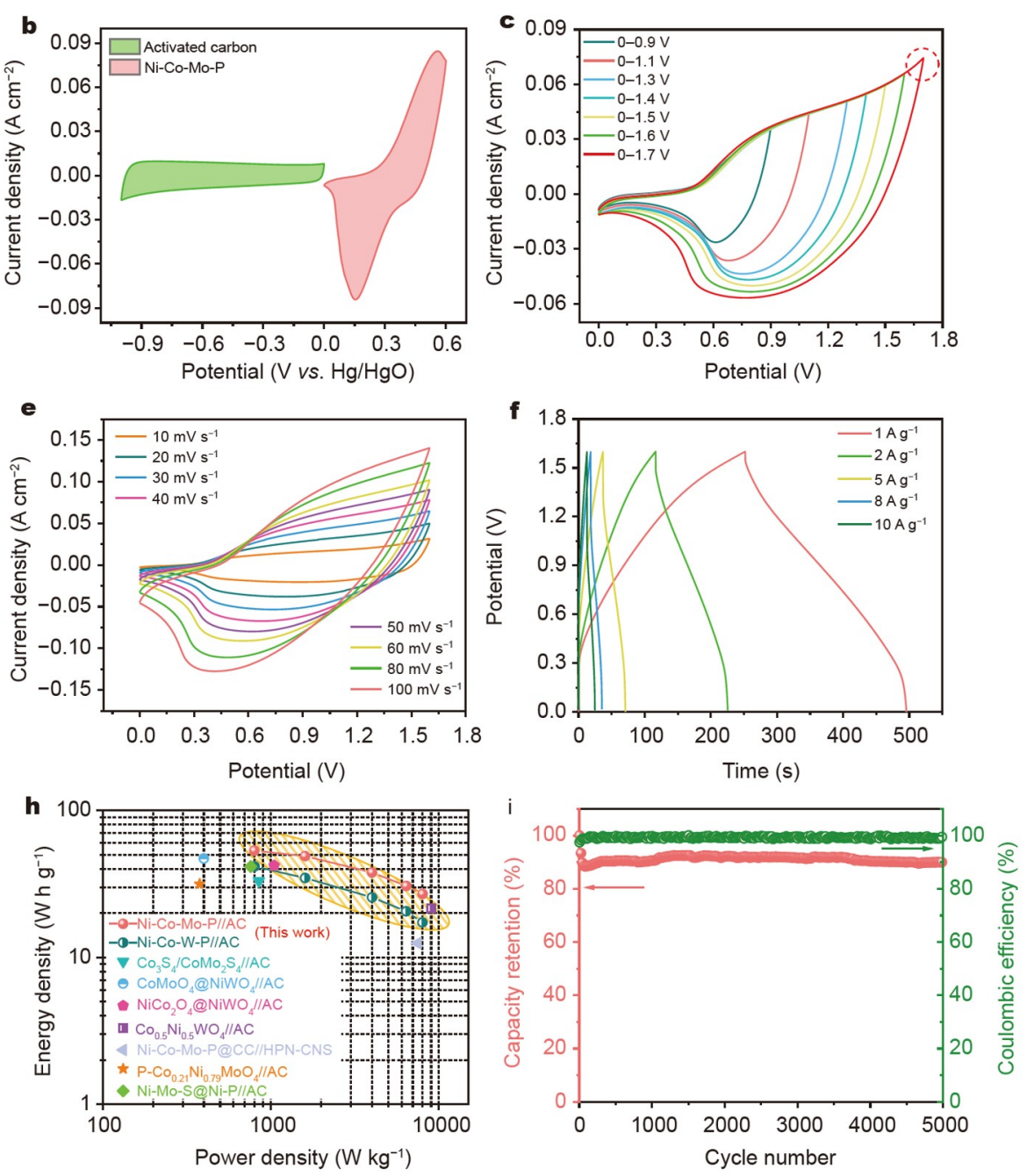

Figure 6 (a) Schematic illustration of Ni-Co-Mo-P//AC HSC. (b) CV curves of Ni-Co-Mo-P and AC at $5 \mathrm{mV} \mathrm{s}^{-1}$. (c) CV curves and (d) GCD curves of Ni$\mathrm{Co}-\mathrm{Mo}-\mathrm{P} / / \mathrm{AC}$ at different voltage windows. (e) $\mathrm{CV}$ curves of Ni-Co-Mo-P//AC at various scan rates. (f) GCD curves of Ni-Co-Mo-P//AC at various current densities. (g) Specific capacities of Ni-Co-Mo-P//AC and Ni-Co-W-P//AC. (h) Ragone plots of Ni-Co-Mo-P//AC, Ni-Co-W-P//AC and other reported devices. (i) Cycling performance of Ni-Co-Mo-P//AC.

density of $1 \mathrm{~A} \mathrm{~g}^{-1}$, which is higher than that of Ni-Co-W-P//AC $\left(187 \mathrm{C} \mathrm{g}^{-1}\right)$. Even at a high current density of $10 \mathrm{~A} \mathrm{~g}^{-1}$, Ni-CoMo-P//AC could maintain a specific capacity of $121 \mathrm{C} \mathrm{g}^{-1}$, while the capacity of Ni-Co-W-P//AC decreases to $78 \mathrm{C} \mathrm{g}^{-1}$. The Ragone plots of Ni-Co-Mo-P//AC and Ni-Co-W-P//AC are compared with some recently reported devices (Fig. 6h), such as $\mathrm{Co}_{3} \mathrm{~S}_{4} / \mathrm{CoMo}_{2} \mathrm{~S}_{4} / / \mathrm{AC} \quad[54], \quad \mathrm{CoMoO}_{4} @ \mathrm{NiWO}_{4} / / \mathrm{AC} \quad$ [43], $\mathrm{NiCo}_{2} \mathrm{O}_{4} @ \mathrm{NiWO}_{4} / / \mathrm{AC}$ [55], $\mathrm{Co}_{0.5} \mathrm{Ni}_{0.5} \mathrm{WO}_{4} / / \mathrm{AC}$ [56], Ni-CoMo-P//HPN-CNS [57], P-Co $\mathrm{Co}_{0.21} \mathrm{Ni}_{0.79} \mathrm{MoO}_{4} / / \mathrm{AC}$ [58], and NiMo-S@Ni-P//AC [59]. Obviously, the energy densities and power densities of Ni-Co-Mo-P//AC and Ni-Co-W-P//AC are superior to those of other devices. Specifically, Ni-Co-Mo-P//AC delivers a remarkable energy density of $53.3 \mathrm{~W} \mathrm{~h} \mathrm{~kg}^{-1}$ at a power density of $800 \mathrm{~W} \mathrm{~kg}^{-1}$, which is higher than that of Ni-Co-W-P// $\mathrm{AC}\left(41.6 \mathrm{~W} \mathrm{~h} \mathrm{~kg}^{-1}\right.$ at $\left.800 \mathrm{~W} \mathrm{~kg}^{-1}\right)$. Even at a high power density of $8003 \mathrm{~W} \mathrm{~kg}^{-1}$, Ni-Co-Mo-P//AC still retains a high energy density of $27 \mathrm{~W} \mathrm{~h} \mathrm{~kg}$. . Fig. 6i shows the cycling performance of $\mathrm{Ni}-\mathrm{Co}-\mathrm{Mo}-\mathrm{P} / / \mathrm{AC}$ at $5 \mathrm{~A} \mathrm{~g}^{-1}$. After 5000 charging/discharging tests, the capacity retention of $\mathrm{Ni}-\mathrm{Co}-\mathrm{Mo}-\mathrm{P} / / \mathrm{AC}$ could reach up to $90 \%$ with an almost $100 \%$ Coulombic efficiency, demonstrating its excellent cycling stability.
An energy conversion and storage system was constructed by a commercial solar cell and the Ni-Co-Mo-P//AC HSC device (Fig. 7a). After being charged by the solar cell in sunshine (Fig. S22), the ZJU (Zhejiang University)-labeled light-emitting diode (LED) board composed of 30 green LED lights was lit by two Ni-Co-Mo-P//AC devices in series (Fig. 7b, c). The LED board exhibits high brightness at the beginning and the brightness decreases gradually after $5 \mathrm{~min}$. However, LED brightness still can be observed after $10 \mathrm{~min}$. When an electronic thermometer and a fan were powered by Ni-Co-Mo-P//AC, they could keep working for a long time (Fig. 7d, e). In addition, we also assembled the flexible all-solid-state HSC (AHSC) using NiCo-Mo-P and AC (Fig. 7f). Fig. 7g depicts the CV curves of the device under bending conditions at $0^{\circ}, 90^{\circ}$ and $180^{\circ}$. Interestingly, negligible difference is observed for these three curves, demonstrating its good flexibility and promising potential in wearable electronics.

\section{CONCLUSIONS}

Novel hetero-structured $\mathrm{Ni}-\mathrm{Co}-\mathrm{Mo}-\mathrm{P}$ and $\mathrm{Ni}-\mathrm{Co}-\mathrm{W}-\mathrm{P}$ nanoarrays are successfully fabricated by incorporating $\mathrm{Mo} / \mathrm{W}$ ele- 


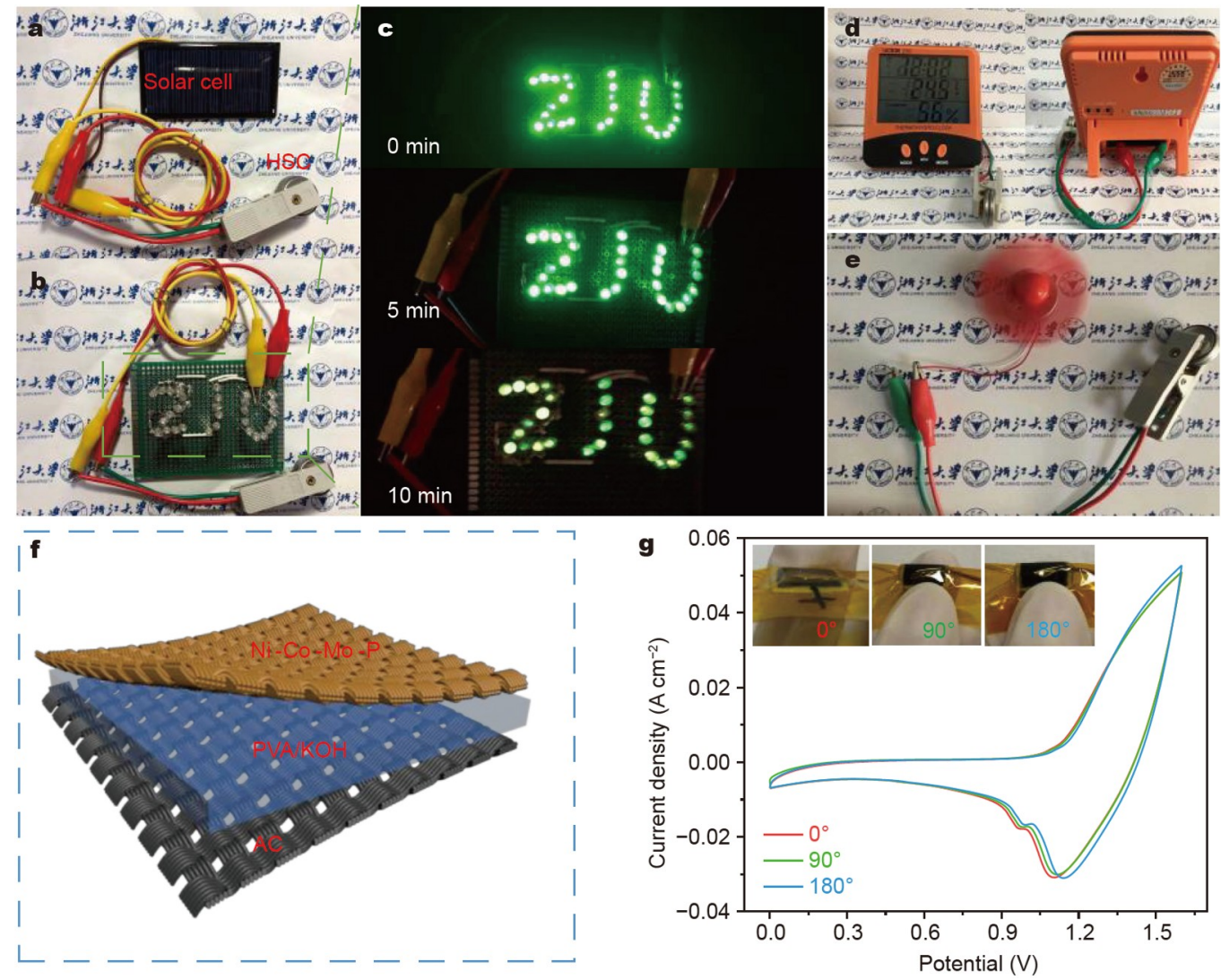

Figure 7 (a) Charging HSC by the solar cell. (b, c) ZJU LED board lit by two HSC devices in series. (d) Electronic thermometer and (e) fan powered by two HSC devices in series. (f) Schematic illustration of the flexible all-solid-state Ni-Co-Mo-P//AC device. (g) Comparative CV curves at different bending angles.

ments into NiCoP nanoarrays, respectively. Compared with the $\mathrm{NiCoP}$ and Ni-Co-W-P counterparts, the resultant Ni-Co-Mo-P heterostructure displays a better electrochemical performance (a high capacity of $4.08 \mathrm{C} \mathrm{cm}^{-2}$ at $2 \mathrm{~mA} \mathrm{~cm} \mathrm{~cm}^{-2}$ and good cycling stability over 3000 cycles), which can be mainly attributed to the increased active sites and enhanced reaction kinetics based on the theoretical and experimental analysis. Moreover, an aqueous $\mathrm{Ni}-\mathrm{Co}-\mathrm{Mo}-\mathrm{P} / / \mathrm{AC}$ HSC could deliver a high energy density of $53.3 \mathrm{~W} \mathrm{~h} \mathrm{~kg}^{-1}$ at a power density of $800 \mathrm{~W} \mathrm{~kg}^{-1}$ and keep excellent cycling stability (a capacity retention of $90 \%$ after 5000 cycles). In addition, an all-solid-state Ni-Co-Mo-P//AC HSC is developed and good flexibility is demonstrated. This work could broaden the design strategy of TMP-based electrode materials to improve the electrochemical performance for HSCs.

\section{Received 12 September 2021; accepted 19 November 2021;} published online 7 January 2022

1 Liu J, Wang J, Xu C, et al. Advanced energy storage devices: Basic principles, analytical methods, and rational materials design. Adv Sci, 2018, 5: 1700322

2 Simon P, Gogotsi Y. Perspectives for electrochemical capacitors and related devices. Nat Mater, 2020, 19: 1151-1163

3 Jin L, Shen C, Shellikeri A, et al. Progress and perspectives on prelithiation technologies for lithium ion capacitors. Energy Environ Sci, 2020, 13: 2341-2362

4 Yuan Y, Wang C, Lei K, et al. Sodium-ion hybrid capacitor of high power and energy density. ACS Cent Sci, 2018, 4: 1261-1265

5 Jia X, Liu C, Neale ZG, et al. Active materials for aqueous zinc ion batteries: Synthesis, crystal structure, morphology, and electro- chemistry. Chem Rev, 2020, 120: 7795-7866

6 Wang C, Liu L, Zhao S, et al. Tuning local chemistry of P2 layeredoxide cathode for high energy and long cycles of sodium-ion battery. Nat Commun, 2021, 12: 2256

7 Tie D, Huang S, Wang J, et al. Hybrid energy storage devices: Advanced electrode materials and matching principles. Energy Storage Mater, 2019, 21: 22-40

8 Muzaffar A, Ahamed MB, Deshmukh K, et al. A review on recent advances in hybrid supercapacitors: Design, fabrication and applications. Renew Sustain Energy Rev, 2019, 101: 123-145

9 Liu JC, Huang ZH, Ma TY. Aqueous supercapacitor with ultrahigh voltage window beyond 2.0 volt. Small Struct, 2020, 1: 2000020

10 Shao Y, El-Kady MF, Sun J, et al. Design and mechanisms of asymmetric supercapacitors. Chem Rev, 2018, 118: 9233-9280

11 Chen $\mathrm{Y}$, Kang C, Ma L, et al. MOF-derived $\mathrm{Fe}_{2} \mathrm{O}_{3}$ decorated with $\mathrm{MnO}_{2}$ nanosheet arrays as anode for high energy density hybrid supercapacitor. Chem Eng J, 2021, 417: 129243

12 Sekhar SC, Ramulu B, Narsimulu D, et al. Metal-organic frameworkderived $\mathrm{Co}_{3} \mathrm{~V}_{2} \mathrm{O}_{8} @ \mathrm{CuV}_{2} \mathrm{O}_{6}$ hybrid architecture as a multifunctional binder-free electrode for Li-ion batteries and hybrid supercapacitors. Small, 2020, 16: 2003983

13 Zhu J, Huang B, Zhao C, et al. Benzoic acid-assisted substrate-free synthesis of ultrathin nanosheets assembled two-dimensional porous $\mathrm{Co}_{3} \mathrm{O}_{4}$ thin sheets with $3 \mathrm{D}$ hierarchical micro-/nano-structures and enhanced performance as battery-type materials for supercapacitors. Electrochim Acta, 2019, 313: 194-204

14 Huang B, Wang W, Pu T, et al. Rational design and facile synthesis of two-dimensional hierarchical porous $\mathrm{M}_{3} \mathrm{~V}_{2} \mathrm{O}_{8}(\mathrm{M}=\mathrm{Co}$, Ni and Co$\mathrm{Ni}$ ) thin sheets assembled by ultrathin nanosheets as positive electrode materials for high-performance hybrid supercapacitors. Chem Eng J, 2019, 375: 121969

15 Pazhamalai P, Krishnamoorthy K, Sahoo S, et al. Copper tungsten 
sulfide anchored on Ni-foam as a high-performance binder free negative electrode for asymmetric supercapacitor. Chem Eng J, 2019, 359: 409-418

16 Sahoo S, Krishnamoorthy K, Pazhamalai P, et al. Copper molybdenum sulfide anchored nickel foam: A high performance, binder-free, negative electrode for supercapacitors. Nanoscale, 2018, 10: 13883-13888

17 Li Y, Luo Z, Liang S, et al. Two-dimensional porous zinc cobalt sulfide nanosheet arrays with superior electrochemical performance for supercapatteries. J Mater Sci Tech, 2021, 89: 199-208

18 Liao F, Zhao X, Yang G, et al. Recent advances on two-dimensional $\mathrm{NiFe}-\mathrm{LDHs}$ and their composites for electrochemical energy conversion and storage. J Alloys Compd, 2021, 872: 159649

19 Zhao Y, Zhao M, Ding X, et al. One-step colloid fabrication of nickel phosphides nanoplate/nickel foam hybrid electrode for high-performance asymmetric supercapacitors. Chem Eng J, 2019, 373: 1132-1143

20 Shi Y, Li M, Yu Y, et al. Recent advances in nanostructured transition metal phosphides: Synthesis and energy-related applications. Energy Environ Sci, 2020, 13: 4564-4582

$21 \mathrm{Qu} \mathrm{G}$, Sun P, Xiang G, et al. Moss-like nickel-cobalt phosphide nanostructures for highly flexible all-solid-state hybrid supercapacitors with excellent electrochemical performances. Appl Mater Today, 2020, 20: 100713

22 Li X, Elshahawy AM, Guan C, et al. Metal phosphides and phosphatesbased electrodes for electrochemical supercapacitors. Small, 2017, 13: 1701530

23 Zhang Q, Liu Z, Zhao B, et al. Design and understanding of dendritic mixed-metal hydroxide nanosheets@N-doped carbon nanotube array electrode for high-performance asymmetric supercapacitors. Energy Storage Mater, 2019, 16: 632-645

24 Xie H, Lan C, Chen B, et al. Noble-metal-free catalyst with enhanced hydrogen evolution reaction activity based on granulated Co-doped $\mathrm{Ni}$ Mo phosphide nanorod arrays. Nano Res, 2020, 13: 3321-3329

25 Lin Y, Sun K, Liu S, et al. Construction of $\mathrm{CoP} / \mathrm{NiCoP}$ nanotadpoles heterojunction interface for wide $\mathrm{pH}$ hydrogen evolution electrocatalysis and supercapacitor. Adv Energy Mater, 2019, 9: 1901213

26 Gao X, Liu X, Wu D, et al. Significant role of Al in ternary layered double hydroxides for enhancing electrochemical performance of flexible asymmetric supercapacitor. Adv Funct Mater, 2019, 29: 1903879

27 Zhu G, Yang L, Wang W, et al. Hierarchical three-dimensional manganese doped cobalt phosphide nanowire decorated nanosheet cluster arrays for high-performance electrochemical pseudocapacitor electrodes. Chem Commun, 2018, 54: 9234-9237

28 Nguyen TT, Balamurugan J, Kim NH, et al. Hierarchical 3D Zn-Ni-P nanosheet arrays as an advanced electrode for high-performance allsolid-state asymmetric supercapacitors. J Mater Chem A, 2018, 6: 86698681

29 Mohammadi Zardkhoshoui A, Hosseiny Davarani SS. A rational design of nanoporous $\mathrm{Cu}-\mathrm{Co}-\mathrm{Ni}-\mathrm{P}$ nanotube arrays and $\mathrm{CoFe}_{2} \mathrm{Se}_{4}$ nanosheet arrays for flexible solid-state asymmetric devices. Dalton Trans, 2020, 49: 10028-10041

30 Li J, Liu Z, Zhang Q, et al. Anion and cation substitution in transitionmetal oxides nanosheets for high-performance hybrid supercapacitors. Nano Energy, 2019, 57: 22-33

31 Zong Q, Zhu Y, Wang Q, et al. Prussian blue analogues anchored P$(\mathrm{Ni}, \mathrm{Co}) \mathrm{Se}_{2}$ nanoarrays for high performance all-solid-state supercapacitor. Chem Eng J, 2020, 392: 123664

32 Elshahawy AM, Guan C, Li X, et al. Sulfur-doped cobalt phosphide nanotube arrays for highly stable hybrid supercapacitor. Nano Energy, 2017, 39: 162-171

33 Zhai T, Wan L, Sun S, et al. Phosphate ion functionalized $\mathrm{Co}_{3} \mathrm{O}_{4}$ ultrathin nanosheets with greatly improved surface reactivity for high performance pseudocapacitors. Adv Mater, 2017, 29: 1604167

34 Wang $\mathrm{F}, \mathrm{Ma} \mathrm{K}$, Tian $\mathrm{W}$, et al. $\mathrm{P}$-doped $\mathrm{NiMoO}_{4}$ parallel arrays anchored on cobalt carbonate hydroxide with oxygen vacancies and mass transfer channels for supercapacitors and oxygen evolution. J Mater Chem A, 2019, 7: 19589-19596

35 Kumar S, Saeed G, Kim NH, et al. Fabrication of Co-Ni-Zn ternary oxide@NiWO 4 core-shell nanowire arrays and $\mathrm{Fe}_{2} \mathrm{O}_{3}$-CNTs@GF for ultra-high-performance asymmetric supercapacitor. Compos Part BEng, 2019, 176: 107223

36 Guo D, Li Z, Wang D, et al. Design and synthesis of zinc-activated $\mathrm{Co}_{x} \mathrm{Ni}_{2-x} \mathrm{P} /$ graphene anode for high-performance zinc ion storage device. ChemSusChem, 2021, 14: 2205-2215

37 Niu R, Wang G, Ding Y, et al. Hexagonal prism arrays constructed using ultrathin porous nanoflakes of carbon doped mixed-valence Co$\mathrm{Mn}-\mathrm{Fe}$ phosphides for ultrahigh areal capacitance and remarkable cycling stability. J Mater Chem A, 2019, 7: 4431-4437

38 He S, Guo F, Yang Q, et al. Design and fabrication of hierarchical NiCoP-MOF heterostructure with enhanced pseudocapacitive properties. Small, 2021, 17: 2100353

39 Wang X, Chai L, Ding J, et al. Chemical and morphological transformation of MOF-derived bimetallic phosphide for efficient oxygen evolution. Nano Energy, 2019, 62: 745-753

40 Liu W, Yu L, Yin R, et al. Non-3d metal modulation of a 2D Ni-Co heterostructure array as multifunctional electrocatalyst for portable overall water splitting. Small, 2020, 16: 1906775

41 Huang $\mathrm{H}$, Cho A, Kim S, et al. Structural design of amorphous $\mathrm{CoMoP}_{x}$ with abundant active sites and synergistic catalysis effect for effective water splitting. Adv Funct Mater, 2020, 30: 2003889

42 Liu S, Yin Y, Ni D, et al. Phosphorous-containing oxygen-deficient cobalt molybdate as an advanced electrode material for supercapacitors. Energy Storage Mater, 2019, 19: 186-196

43 Hsu FH, Hsu SY, Pao CW, et al. Electrochemical properties and mechanism of $\mathrm{CoMoO}_{4} @ \mathrm{NiWO}_{4}$ core-shell nanoplates for high-performance supercapacitor electrode application studied via in situ X-ray absorption spectroscopy. Nanoscale, 2020, 12: 13388-13397

$44 \mathrm{Xu} \mathrm{W}$, Sun $\mathrm{C}$, Wang N, et al. Sn stabilized pyrovanadate structure rearrangement for zinc ion battery. Nano Energy, 2021, 81: 105584

45 Cao J, Zhang D, Yue Y, et al. Oxygen defect enriched $\left(\mathrm{NH}_{4}\right)_{2} \mathrm{~V}_{10} \mathrm{O}_{25}$. $8 \mathrm{H}_{2} \mathrm{O}$ nanosheets for superior aqueous zinc-ion batteries. Nano Energy, 2021, 84: 105876

46 Wang $\mathrm{X}, \mathrm{Li} \mathrm{Y}$, Wang $\mathrm{S}$, et al. $2 \mathrm{D}$ amorphous $\mathrm{V}_{2} \mathrm{O}_{5} /$ graphene heterostructures for high-safety aqueous $\mathrm{Zn}$-ion batteries with unprecedented capacity and ultrahigh rate capability. Adv Energy Mater, 2020, 10: 2000081

47 Liu S, Zhu H, Zhang B, et al. Tuning the kinetics of zinc-ion insertion/ extraction in $\mathrm{V}_{2} \mathrm{O}_{5}$ by in situ polyaniline intercalation enables improved aqueous zinc-ion storage performance. Adv Mater, 2020, 32: 2001113

48 Singh AK, Sarkar D, Karmakar K, et al. High-performance supercapacitor electrode based on cobalt oxide-manganese dioxide-nickel oxide ternary 1D hybrid nanotubes. ACS Appl Mater Interfaces, 2016, 8: 20786-20792

49 Gao L, Song J, Surjadi JU, et al. Graphene-bridged multifunctional flexible fiber supercapacitor with high energy density. ACS Appl Mater Interfaces, 2018, 10: 28597-28607

50 Naderi L, Shahrokhian S. Nickel vanadium sulfide grown on nickel copper phosphide dendrites/Cu fibers for fabrication of all-solid-state wire-type micro-supercapacitors. Chem Eng J, 2020, 392: 124880

51 Ren Y, Zhu T, Liu Y, et al. Direct utilization of photoinduced charge carriers to promote electrochemical energy storage. Small, 2021, 17: 2008047

52 Yang $\mathrm{F}$, Liu $\mathrm{X}$, Zhang $\mathrm{H}$, et al. Boosting oxygen catalytic kinetics of carbon nanotubes by oxygen-induced electron density modulation for advanced Zn-air batteries. Energy Storage Mater, 2020, 30: 138-145

53 Geng $\mathrm{H}$, Cheng $\mathrm{M}$, Wang B, et al. Electronic structure regulation of layered vanadium oxide via interlayer doping strategy toward superior high-rate and low-temperature zinc-ion batteries. Adv Funct Mater, 2019, 30: 1907684

54 Yang $\mathrm{X}$, Sun $\mathrm{H}$, Zan $\mathrm{P}$, et al. Growth of vertically aligned $\mathrm{Co}_{3} \mathrm{~S}_{4} /$ $\mathrm{CoMo}_{2} \mathrm{~S}_{4}$ ultrathin nanosheets on reduced graphene oxide as a highperformance supercapacitor electrode. J Mater Chem A, 2016, 4: $18857-18867$

55 Chen S, Yang G, Jia Y, et al. Three-dimensional $\mathrm{NiCo}_{2} \mathrm{O}_{4} @ \mathrm{NiWO}_{4}$ core-shell nanowire arrays for high performance supercapacitors. J Mater Chem A, 2017, 5: 1028-1034

56 Huang B, Wang $\mathrm{H}$, Liang $\mathrm{S}$, et al. Two-dimensional porous cobaltnickel tungstate thin sheets for high performance supercapattery. En- 
ergy Storage Mater, 2020, 32: 105-114

57 Yang Y, Zhou Y, Hu Z, et al. 3D thin-wall cell structure nickel-cobaltmolybdenum ternary phosphides on carbon cloth as high-performance electrodes for asymmetric supercapacitors. J Alloys Compd, 2019, 772: 683-692

58 Xing $\mathrm{T}$, Ouyang $\mathrm{Y}$, Chen $\mathrm{Y}$, et al. P-doped ternary transition metal oxide as electrode material of asymmetric supercapacitor. J Energy Storage, 2020, 28: 101248

59 Lei X, Ge S, Yang TY, et al. Ni-Mo-S@Ni-P composite materials as binder-free electrodes for aqueous asymmetric supercapacitors with enhanced performance. J Power Sources, 2020, 477: 229022

Acknowledgements This work was financially supported by the National Natural Science Foundation of China (51772267), and the Science and Technology Program of Guangxi Zhuang Autonomous Region (ZD20302001).

Author contributions Zong Q and Tao D designed and prepared the samples; Zhan J and Liu X performed the characterizations; Yang $\mathrm{H}$ and Wang J finished the first-principles calculation; Zong Q and Tao D performed data analysis and wrote the paper with support from Zhang Q and Cao G. All authors contributed to the general discussion.

Conflict of interest The authors declare that they have no conflict of interest.

Supplementary information Supporting data are available in the online version of the paper.

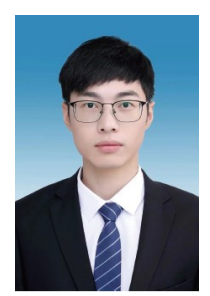

Quan Zong received his $\mathrm{PhD}$ degree (2021) from the School of Materials Science and Engineering, Zhejiang University. $\mathrm{He}$ is currently working at the College of Materials and Chemistry, China Jiliang University. His current research interests include the synthesis and characterization of nanomaterials for electrochemical energy conversion and storage technologies.

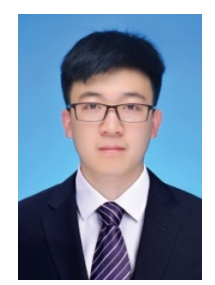

Daiwen Tao received his MS degree from Northwest Normal University, China, in 2020. Afterwards, he joined Prof. Qilong Zhang's group at Zhejiang University, China, for pursuing his $\mathrm{PhD}$ degree in materials science and engineering. His research interests focus on the electrochemical energy storage devices and their application in renewable energy storage and hybrid-electric vehicles.

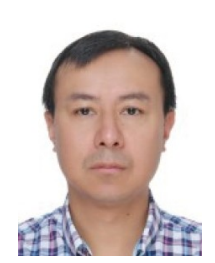

Qi-Long Zhang received his $\mathrm{PhD}$ degree in materials science and engineering from Zhejiang University, China. $\mathrm{He}$ is currently a professor at Zhejiang University, China. His main research interests focus on novel organic-inorganic nanocomposites for energy-storage, energy harvesting and flexible sensors, electric ceramics/thin films and micro-devices for modern communication.

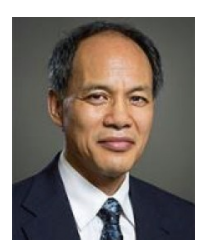

Guozhong Cao is a Boeing-Steiner Professor of materials science and engineering, Professor of chemical engineering and adjunct, Professor of mechanical engineering at the University of Washington. His current research focuses on chemical processing of nanomaterials for solar cells, batteries, and supercapacitors as well as actuators and sensors for aviation and biomedical applications.

\section{引入Mo/W优化形貌并构建异质结构提高 $\mathrm{NiCoP}$ 作为 混合电容器电极的电化学性能}

宗泉 ${ }^{1,2 \dagger^{*}}$, 陶代文 ${ }^{2 \dagger}$, 杨辉 ${ }^{2,3}$, 詹建辉 ${ }^{2}$, 刘雄 ${ }^{2}$, 王疆瑛 ${ }^{1}$, 张启 龙 $^{2,3^{*}}$, 曹国忠 ${ }^{4 *}$

摘要 过渡金属磷化物具有高电导率和高电化学活性, 是一类新兴的 混合电容器电极材料. 然而制备具有快速反应动力学和稳定结构的过 渡金属磷化物仍然是一大挑战. 本文将 $\mathrm{Mo}$ 或 $\mathrm{W}$ 引入到 $\mathrm{NiCoP}$ 中, 得到 具有三维开放结构的纳米阵列和优化电子结构的异质结构. 相比于 $\mathrm{Ni}$ $\mathrm{CoP}$ 纳米阵列, $\mathrm{Ni}-\mathrm{Co}-\mathrm{Mo}-\mathrm{P}$ 或 Ni-Co-W-P纳米阵列具有更大的比表面 积和更多的空隙, 这种独特的结构不仅有助于电解液的渗透, 还可以缓 解氧化还原过程中的体积变化. 密度泛函理论计算结果显示引入高价 $\mathrm{Mo}$ 或 $\mathrm{W}$ 元素形成异质结构提高了材料的本征电导率, 加快了反应动力 学. $\mathrm{Ni}-\mathrm{Co}-\mathrm{Mo}-\mathrm{P}$ 纳米阵列在 $2 \mathrm{~m} \mathrm{~A} \mathrm{~cm}^{-2}$ 的电流密度下表现出 $4.08 \mathrm{C} \mathrm{cm}^{-2}\left(703 \mathrm{C} \mathrm{g}^{-1}\right)$ 的高面积比容量; 在 $30 \mathrm{~mA} \mathrm{~cm}$ 灰, 比容量还 能保持在 $3.25 \mathrm{C} \mathrm{cm}^{-2}$. 此外, Ni-Co-Mo-P纳米阵列与活性炭组装成的 水系混合超级电容器表现出 $800 \mathrm{~W} \mathrm{~kg}$-1的高能量密度. 本研究为高性 能过渡金属磷化物基电极材料的设计拓宽了思路, 有助于促进其在混 合电容器中的应用. 